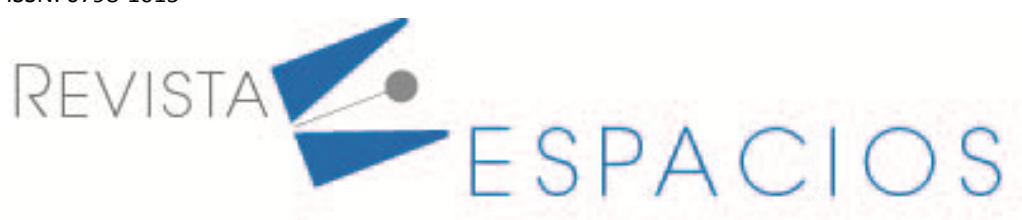

\title{
Propuesta de asociatividad para productores hortícolas en Colombia
}

\section{Associativity proposal for horticultural producers in Colombia}

\author{
SERRANO AMADO, Ana M. ${ }^{1}$ \\ MARTINEZ BERNAL, Martha S. ${ }^{2}$ \\ TIUZO, Sandra C. ${ }^{3}$ \\ PINEDA CALIXTO, Derly Y. ${ }^{4}$
}

\begin{abstract}
Resumen
El departamento de Boyacá, para el año 2018 presenta una producción de hortalizas varias de 796.03 (ton) ocupando 172.00 (ha), con un rendimiento de 4.63 (ton/ha), y un \% de participación en producción nacional de 4.14\%. Según el Ministerio de Agricultura, (2018) el departamento de Boyacá es el primer productor de hortalizas en el país, ya que el $52 \%$ del área total hortícola se aglutina en los departamentos de Boyacá (15\%), Cundinamarca (16\%), Antioquia (11\%) y Nariño (10\%), mientras que el $58 \%$ del volumen producido en hortalizas se condensa en: Boyacá (22\%), Antioquia (20\%) y Cundinamarca (16\%). Antioquia y Boyacá, alcanzan rendimientos superiores en más de un $50 \%$ del promedio nacional, actualmente se presenta perdida de hortalizas hasta del $30 \%$, problemáticas en proceso de mercadeo, producción, generando causas en poscosecha, empaque, saturación en el mercado, creando como problemática relevante el trabajo individual y la falta de asociación de los horticultores. Debido a los anterior el grupo de investigación Management de la Universidad Pedagógica y Tecnológica de Colombia realizo la investigación con el fin de caracterizar a los productores hortícolas del municipio de Sogamoso, con el ánimo de hacer una propuesta de asociatividad, con aras al mejoramiento de problemas de mercadeo, asociación y técnicos.
\end{abstract}

Palabras clave: asociatividad agropecuaria, productores hortícolas, cadenas productivas.

\begin{abstract}
The department of Boyacá, (2018) eld of 4.63 (ton / ha), and a\% participation in presents a production of various vegetables of 796.03 (ton) occupying 172.00 (ha), with a yinational production of $4.14 \%$. According to the Ministry of Agriculture, (2018) the department of Boyacá is the first producer of vegetables in the country, since $52 \%$ of the total horticultural area is agglutinated in the departments of Boyacá (15\%), Cundinamarca (16\%), Antioquia (11\%) and Nariño (10\%), while 58\% of the volume produced in vegetables is condensed in: Boyacá (22\%), Antioquia (20\%) and Cundinamarca (16\%). Antioquia and Boyacá, reach higher yields in more than $50 \%$ of the national average, currently there is a loss of vegetables up to $30 \%$, problems in the marketing process, production, generating causes in post-harvest, packaging, saturation in the market, creating as relevant problem individual work and lack of association of horticulturists. Due to the above, the Management research group of the Pedagogical and Technological University of Colombia carried out the research in order to characterize the
\end{abstract}

\footnotetext{
${ }^{1}$ Docente Investigadora. Escuela de Administración de Empresas Agropecuarias . Universidad Pedagógica y Tecnológica de Colombia. ana.serrano@uptc.edu.co

${ }^{2}$ Docente. Escuela de Administración de Empresas. Universidad Pedagógica y Tecnológica de Colombia. Martha.martinez@uptc.edu.co ${ }^{3}$ Docente. Escuela de Administración de Empresas. Universidad Pedagógica y Tecnológica de Colombia. sandra.tiuzo@uptc.edu.co

${ }^{4}$ Docente. Escuela de Administración de Empresas. Universidad Pedagógica y Tecnológica de Colombia. derly.pineda01@uptc.edu.co
} 
horticultural producers of the municipality of Sogamoso, with the aim of making a proposal for associativity, in order to improve problems of marketing, association and technicians.

Keywords: agricultural associativity, horticultural producers, productive chains.

\section{Introducción}

El desarrollo agrícola constituye uno de los instrumentos más eficaces para poner fin a la pobreza extrema, impulsar la prosperidad compartida y alimentar a una población que se espera llegue a 9700 millones de habitantes en 2050. El crecimiento de la agricultura es entre dos y cuatro veces más eficaz que el de otros sectores para incrementar los ingresos de los más pobres. Según análisis realizados en 2016, el $65 \%$ de los adultos pobres que trabajan vive de la agricultura. (Banco Mundial, 2019). En los últimos años, las tasas de crecimiento de la producción agropecuaria mundial y los rendimientos de los cultivos han disminuido. Esto ha suscitado temores de que el mundo no sea capaz de incrementar lo suficiente la producción de alimentos y otros productos para asegurar una alimentación adecuada de la población futura.

La disminución no se ha producido a causa de la escasez de tierra o agua, sino más bien debido a que la demanda de productos agropecuarios ha disminuido. Las tasas de crecimiento de la población mundial han ido disminuyendo desde finales de los años sesenta y en muchos países se están alcanzando ahora niveles bastante altos de consumo de alimentos per cápita, por encima de los cuales incrementos adicionales serán limitados. Además, una parte persistentemente alta de la población mundial sigue sumida en una pobreza absoluta y carece de los ingresos necesarios para transformar sus necesidades en una demanda efectiva. (FAO, 2015).

En Colombia, de acuerdo al Banco de la República, en el año 2018 la economía colombiana en general registró una tasa de crecimiento de 2,7\%, lo que significa una relativa consolidación de la dinámica económica, luego de la desaceleración que tuvo lugar en los años anteriores, originada por el fuerte choque a los términos de intercambio, que redujo el crecimiento anual desde un 4,7\% en 2014 al 1,4\% en 2017. La recuperación registrada durante el 2018 fue principalmente impulsada por el crecimiento de la demanda interna (consumo de los hogares y consumo público) y por el incremento de la inversión en el segundo semestre de 2018 (Banco de España, 2019)

Por otro lado, según un informe presentado por (Banrep, 2017) el sector agropecuario representó el 6,3\% del producto interno bruto (PIB) nacional. Los ciclos de crecimiento y contracción del PIB del sector están, en gran medida, determinados por el comportamiento de la producción de café, la cual aporta un $9 \%$ del valor total del agregado agropecuario. La producción de caña de azúcar tiene una participación de 3\%, mientras que el resto de la actividad agrícola tiene una participación del $49 \%$ y ha presentado un crecimiento promedio de $2,6 \%$ desde el año 2000. Se destaca su dinamismo en 2017, cuando alcanzó un incremento anual de 8,1\%. De la misma manera con base en el Censo agropecuario (DANE, 2014) Colombia cuenta con 43.1 millones de hectáreas aptas o destinadas a agricultura, de las cuales tiene cultivadas 7.1 millones (es decir 6.3\% del área nacional).

Es importante resaltar lo mencionado por (Villanueva, 2018) quien afirma que según un estudio realizado por FINAGRO, se identificaron 15 productos fundamentales para el desarrollo del sector (FINAGRO, 2014): Arroz, Banano y plátano, Cacao, Café, Caña de azúcar y de panela, Maíz Palma de aceite, Flores, Frutales, Hortalizas, Ganadería doble propósito, Ganadería leche, Porcicultura, Avicultura y Piscicultura.

El desarrollo de estos productos agropecuarios, generan 2,1 millones de empleos directos, lo que representa el $80 \%$ del total del sector agrícola y pecuario. Asimismo, se considera que estos productos permitirán a futuro incrementar en más de un millón de hectáreas la superficie cultivada del país y, de acuerdo a estimaciones de FINAGRO, generarán aproximadamente 291 mil nuevos empleos para 2020. 
Según estadísticas de (Agronet, 2019) en Colombia para el año 2017 la producción de hortalizas varias fue de 52784.75 (ton) ocupando 4157.02 (ha), con un rendimiento de 12.7 (ton/ha), por lo cual se establece una disminución significativa en cuanto al año anterior debido a que la producción promedio fue de 98426.97 (ton) ocupando 8594.55 (ha) a diferencia que el rendimiento fue menos con una participación de 11.45 (ton/ha).En Boyacá, para el año 2018 la producción de hortalizas varias fue de 796.03 (ton) ocupando 172.00 (ha), con un rendimiento de 4.63 (ton/ha), y un \% de participación en producción nacional de $4.14 \%$.

El total de hectáreas sembradas en el municipio de Sogamoso durante el año 2018 fue de 1.195 ha, siendo el $6,71 \%$, en cuanto la papa, maíz, pastos con un 50\%;17\%;10, seguidos de cebolla, el frijol, la arveja, otros productos y finalmente las hortalizas, destacándose las veredas de Mortiñal, Primera y Segunda Chorrera, Cintas, Ombachita, Pilar y Ceibita. Para el caso de la cebolla las veredas son Siatáme, San José de Porvenir, Monquirá y Segunda Chorrera (CONDÍA, 2016, p. 125). Sin embargo este sector hortícola en el municipio de Sogamoso presenta problemáticas "por la falta de inyectarle a la producción un valor agregado, el ingreso de los productores es bajo con relación a su sistema productivo, no existe una finalidad expansiva-productiva que favorezca los rendimientos financieros de los agricultores"(Condía, 2016.p.130), adicional a esto se presentan la baja trasmisión de tecnología a la producción primaria, la perdida de la vocación agrícola, la distorsión de la cadena productiva y comercial, infraestructura inadecuada para realizar el proceso de producción que cumpla con los estándares de calidad y la falta de trabajo organizado y asociativo, dado que estos productores carecen de conocimiento referente al tema de la asociatividad, presentan una actitud y acciones de rechazo debido a las malas experiencias vividas. Con estas problemáticas se evidencia que el sistema de producción hortícola presente estacionalidad y perdidas de los productos.

Para el desarrollo de la investigación se implementa una metodología mixta, desarrollada en dos fases, se da inicio con el análisis documental de los diferentes modelos de asociatividad con el fin de apropiar el mas adecuado, como segunda fase se realiza una caracterización de los productores hortícolas la cual se desarrolla en tres etapas (nivel económico, el producto y el tema de asociatividad) una vez consolidada esta información se detectan as falencias e inconvenientes que presenta los productores hortícolas con el animo del diseño de una propuesta de asociatividad.

\subsection{Fundamentación Teórica}

\section{Asociatividad}

Es imprescindible establecer el valor de la asociatividad dentro del contexto empresarial en el marco agropecuario, por tal razón (González, 2018) afirma "cuán importante es utilizar la estrategia de asociarse en el sector de la agricultura para lograr mejorar ingresos económicos, sin embargo, en ocasiones se necesita conocer el verdadero impacto que tiene la asociatividad en las aspiraciones de bienestar de los agricultores". Por ello es fundamental reconocer aspectos generales que conforma la asociatividad, para lo cual se determinan antecedentes significativos que han generado como resultados una serie de procesos, herramientas, conceptos y teorías desarrollados en el ámbito empresarial.

De esta manera se resalta lo afirmado por (Narváez et al., 2009) quienes expresan que "desde finales del siglo $X X$ e inicios del siglo XXI, la experiencia asociativa a nivel de las pequeñas y medianas empresas, se ha convertido a nivel mundial en el rasgo distintivo de sobrevivencia y crecimiento de organizaciones". Así mismo (Liendo \& Martínez, 2013) afirma "los cambios estructurales acontecidos en nuestro país desde la década del 90, han producido modificaciones en las condiciones en que opera la economía que han obligado a las Pymes a un replanteo estratégico para adaptarse a las nuevas exigencias competitivas". 
Con base en lo anterior se puede establecer que la asociatividad surge como respuesta a los cambios que generaron la globalización, frente a esto, las pequeñas y medianas empresas se vieron en la obligación de generar estrategias que permitieran aumentar la competitividad.

"A partir de la década de los 80, se han venido desarrollando a nivel mundial distintos esfuerzos por lograr implementar procesos asociativos y los mecanismos han evolucionado y se han desarrollado nuevas formas de asociatividad" (Catellanos et al., 2010)

Por otro lado (Acevedo \& Buitrago, 2009) afirman que "ante la globalización y las crisis de economías, se generaron procesos en los que los países se dieron cuenta de la necesidad de buscar nuevos enfoques, que apoyen a las empresas pequeñas y medianas, surgiendo así, la asociatividad empresarial".

De acuerdo a lo anterior, cabe señalar que como resultado de una fase de transformación a nivel global se establecieron estrategias para que las pequeñas y medianas empresas pudieran sobrevivir a tales cambios como lo menciona (Montoya, 2010)

Los crecientes avances científicos, el cambio tecnológico, la economía globalizada y el desarrollo industrial son elementos dinámicos que, en el panorama mundial, están determinando la capacidad productiva y competitiva de los países, y provocando ajustes en el desarrollo de las relaciones comerciales entre éstos. Una de las estrategias empresariales más efectivas para operar ante tales condiciones, de manera exitosa y rentable, es la asociatividad empresarial.

A partir de la década de los 80 , se han venido desarrollando a nivel mundial distintos esfuerzos por lograr implementar procesos asociativos y los mecanismos han evolucionado y se han desarrollado nuevas formas de asociatividad

Por otro lado, a nivel mundial, en materia de asociatividad, "la Cooperación Internacional ha jugado un rol importante para fortalecer las estrategias de desarrollo local y de organización para la participación comunitaria". (Agencia Presidencial de Cooperación, 2016)

Con base en lo anterior, es de resaltar que el trabajo desarrollado por la Cooperación Internacional ha permitido promover modelos de asociatividad en diferentes países, los cuales están orientados a generar impactos en comunidades de diferentes zonas.

Del mismo modo la (Agencia Presidencial de Cooperación, 2016) afirma que en esta participación con enfoque asociativo se destacan:

Experiencias de la Unión Europea, Canadá, las Agencias de Desarrollo Local (ADEL), el Banco Mundial, la Organización de las Naciones Unidas para la Alimentación y la Agricultura (FAO) y el proceso desarrollado en el municipio de Belén de Umbría, en el marco del programa Territorios de Aprendizaje. Los aprendizajes de estas experiencias coinciden en reconocer la asociatividad como fuente de desarrollo socioeconómico y como un modelo generador de capital social; elemento indispensable para llevar a cabo cualquier tipo de iniciativa que promueva la creación de espacios para la cooperación entre personas, instituciones y distintos actores que trabajan enfrentando los retos de desarrollo en los territorios (p. 8)

En Colombia, Según (Ministerio de agricultura y desarrollo Rural, 2017) de acuerdo a la Resolución 464 de 2017, por la cual se adoptan los lineamientos estratégicos de política pública para la Agricultura Campesina Familiar y Comunitaria establece que "Se fomentará y fortalecerá la asociatividad como la principal herramienta para generar capital social, fortalecer la producción, transformación, financiación y comercialización de los productos y servicios de ACFC, y para estimular los conocimientos y prácticas de protección del medio ambiente". Para la (Agencia Presidencial de Cooperación, 2016) es importante resaltar que:

La Asociatividad ha sido ampliamente reconocida como una estrategia clave para el desarrollo rural sostenible, ya que representa una oportunidad en la construcción de capital social y 
generación de economías de escala para los pequeños productores y campesinos más empobrecidos, lo que permite el mejoramiento de su capacidad productiva, competitiva y el acceso a mercados.

En cuanto al sector agropecuario, (Moreno et al., 2011), afirman que "los pequeños productores generan al menos un 40\% de la producción agropecuaria del país (con una importante participación en frutas, hortalizas, café, caña panelera, maíz, plátano, tubérculos y en ganadería de leche)". Es por ello que se requiere generar formas asociativas que incrementen la participación de aquellas herramientas administrativas, técnicas y financieras para causar impactos en la sociedad.

Para (Steiner \& Ramírez, 2019), en Colombia existen modelos asociativos que surgen tanto por iniciativa privada como a partir de diferentes programas gubernamentales. Desde el gobierno se han diseñado diversas políticas y programas orientados a la creación y/o promoción de modelos asociativos. Entre estos se destacan el Programa Apoyo a Alianzas Productivas (PAAP), el Programa de Transformación Productiva (PTP) y el programa Agricultura por Contrato, Coseche y Venda a la Fija. Sin embargo, pese a estos programas, no hay que desconocer la problemática real por la cual pasa sector agropecuario. (Perfetti et al., 2013) expone que en el caso Colombiano "los pequeños productores enfrentan fallas de mercado adicionales que les dificultan el acceso a tierra y al capital. Adicionalmente, se encuentran en un contexto marcado por una precaria oferta de bienes públicos, servicios sociales y débil presencia de la institucionalidad estatal".

Es por ello que (Grueso et al., 2012) quienes citan (Ministerio de Comercio, Industria y Turismo de Colombia, 2006) afirman que "participar en un proceso de asociatividad facilita la utilización de servicios especializados de tecnología, compra de insumos, diseño, comercialización, financiamiento y mejora de procesos industriales; ser parte de este tipo de procesos permite tener una estructura más sólida y competitiva". Los productores tienen ciertas ventajas cuando están inmersos en estrategias de asociatividad, según (Arias et al., 2010) "tienen un altísimo potencial gerencial para comportarse dentro del sector, responden a cambios en la demanda y a la competencia con innovación en procesos y productos, puede llegar a producir bienes de inversión y llegar a tener incidencia en el mercado". Teniendo en cuenta lo anterior, se puede determinar que la asociatividad en Colombia es una herramienta eficaz que a través de mecanismos permiten aumentar la competitividad.

No obstante, al no manejar procesos asociativos de manera adecuada, con las herramientas necesarias y la participación voluntaria de cada uno de los integrantes teniendo en cuenta metas unificadas es posible que se generen dificultades en el proceso de integración y logro de los objetivos propuestos, por ello afirma que:

A pesar de reconocerse el aporte que realiza la asociatividad para el desarrollo del medio rural, algunas de las organizaciones que se constituyen bajo formas asociativas no logran prosperar, posiblemente por el bajo capital social y relacional, el desconocimiento de los beneficios de organizaciones alternativas, y la baja capacidad [...] (p. 2)

Por otro lado, se destacan los aportes de algunos autores para el concepto de asociatividad:

Para (IICA, 2017) la asociatividad se caracteriza por ser de incorporación voluntaria y de libre unión, donde personas, productores o empresas se organizan en la búsqueda de objetivos comunes, manteniendo la independencia legal y gerencial de sus propias operaciones. En relación con la asociatividad con enfoque empresarial, esta tiene como objetivo el mejorar la competitividad de los asociados en los mercados, con el fin de aumentar los retornos de sus operaciones, incrementar el bienestar familiar y contribuir al desarrollo económico de las comunidades rurales.

Así mismo (Mamani, 2017) afirma que en el Informe 2000 del PNUD se menciona que desde un punto de vista operacional, una organización asociativa es entendida como: "Aquella organización voluntaria y no remunerada de personas o grupos que establecen un vínculo explícito, con el fin de conseguir un objetivo común". Para (Rojas, 2013) los procesos asociativos se pueden entender como todo aquel procedimiento productivo en el que se ve 
involucrado, la cooperación, la confianza, y el trabajo en equipo de diferentes grupos de personas, encaminadas a mejorar el bienestar de los individuos que participan del proceso de transformación de un bien o servicio, que tenga como fin la calidad en el producto final del cliente.

Del mismo modo (Rosales, 1997) afirma que la asociatividad es un mecanismo de cooperación entre empresas micro, pequeñas y medianas, en donde cada empresa participante, manteniendo su independencia jurídica y autonomía gerencial, decide voluntariamente participar en un esfuerzo conjunto con los otros participantes para la búsqueda de un objetivo común. De igual manera (Enrique, 2002) reconoce la asociatividad como una estrategia orientada a potenciar el logro de una ventaja competitiva por medio de la cooperación o el establecimiento de nuevos acuerdos con otras empresas para efectuar ciertas actividades dentro de la cadena de producción; dicha estrategia conduce a un posicionamiento de la empresa en un mercado nacional e internacional.

El esfuerzo conjunto de los participantes en la asociatividad puede materializarse de distintas formas, desde la contratación de un agente de compras o vendedor pagado conjuntamente, hasta la formación de una empresa con personalidad jurídica y patrimonio propio que permita acceder a financiamiento con requisitos de garantías, o para la comercialización de Productos (Arango \& Martinez, 2007)

En igual sentido, (Rodríguez, 2001) considera que la organización de los pequeños productores es ahora un tema esencial tanto en lo que respecta a sus posibilidades de asociación a través de clúster y otras formas (agremiación) que les permitan tener voz y mayor visibilidad ante los diseñadores de políticas.

Por su parte (Landini, 2016) se enfatiza en la necesidad de implementar estrategias asociativas para mitigar o solventar problemáticas como falta en el volumen de producción o alcanzar estándares de calidad exigidos por el mercado. De la misma manera el encadenamiento como resultado de procesos asociativos en las comunidades, puede llevar al mejoramiento de los productos, aumentando el valor agregado de los mismos.

Sin embargo (Maldovan \& Dzembrowski, 2009) afirma "la gran diferencia entre el proceso asociativo y empresas es la producción de bienes y servicios. Para las empresas, el bien o servicio genera el vínculo social, mientras que, para el asociativo proceso, el vínculo social genera el bien o servicio".

\section{Productores de Hortalizas}

Según (Montaña, 2016) el diagnóstico de libre competencia de la cadena productiva de Hortalizas en Colombia en términos generales, la horticultura es una actividad con altos niveles de riesgo que se caracteriza por los siguientes aspectos: cultivos de tamaño pequeño (1/2 - 10 Has), dispersos, uso intensivo de mano de obra, altos costos de producción, mercado inestable y variable, carencia de tecnología apropiada, manejo pos cosecha deficiente y debilidad empresarial y gremial.

De acuerdo a (Corporación Colombia Internacional, 2006) La característica principal de los productores hortícolas, salvo algunas especies, es que se desarrollan en espacios de 1 a 2 hectáreas, y en muchos casos menores. Cultivos que exigen por rentabilidad mayores extensiones se localizan en el rango 2.1 a 5 hectáreas.

El primer actor de la cadena corresponde al cultivador, responsable de adelantar los procesos de producción en distintas etapas o actividades principales. Según el tipo de cultivo y la zona, presenta algunas características distintas respecto a las prácticas o técnicas utilizadas. En su mayoría son cultivadores tradicionales, con varios años de experiencia en el cultivo, en el caso de quienes suministran productos de frutas y verduras para el consumo alimentario a Bogotá, 95\% pertenece a esta categoría, mientras que 5\% corresponde a productores tecnificados. El cultivador hortícola está sujeto al precio de oferta, determinado por el intermediario, en parte 
porque tiene que vender el día de madurez del producto, debido a que no cuenta con posibilidades de almacenamiento. En algunos productos como vegetales de hoja, tomate, plantas aromáticas de uso culinario y otros, el cultivador puede actuar como intermediario, manejando las relaciones con mayoristas, pero en casi todos los casos, cuando sus productos se dirigen a centrales mayoristas, vende en puerta de finca y en menor nivel a plazas de mercado.

Por otro lado, en países como Costa Rica, estos productores están categorizados en 3 grupos: el primero, con más de 10 años de experiencia en el sector, está dedicado exclusivamente a esta actividad, utiliza mano de obra familiar, cultiva alrededor de una hectárea, diversifica la producción, se encuentra agremiado y certificado y tiene la escolaridad más baja, comparada con los otros grupos. El productor del segundo grupo se caracteriza por tener alrededor de 7 años en la actividad y dedicación casi exclusiva, hace poco uso de la mano de obra familiar, cultiva menos de media hectárea, no está necesariamente agremiado y/o certificado y posee un nivel de escolaridad intermedio. El tercer grupo corresponde a productores con menos años de experiencia en esta actividad y la más baja dedicación a la misma; hacen menos uso de la mano de obra familiar; tienen el área de cultivo más pequeña y diversifican poco la producción; pueden o no estar agremiados y/o certificados; poseen la más alta escolaridad. (Camacho et al., 2015)

En cuanto la producción hortícola a nivel mundial se destaca lo mencionado por (Arvizu et al., 2017) en su artículo "Análisis de producción y comercialización hortícola del estado de Puebla: un enfoque de cadena de valor" en México: El estudio recopiló la información de algunos agentes que participan en la cadena de valor de la producción- comercialización de hortalizas (servicios externos, producción- cosecha y comercialización) en donde se identificó que: una estrategia de cooperación para la mejora de la cadena de valor hortícola en la región de estudio debería considerar el rediseño de la cadena de suministro y logística de sus actividades productivas y de comercialización para garantizar una mejor distribución y accesibilidad de los alimentos. Debido a la baja escolaridad de los sujetos de estudio, la enseñanza en innovación tecnológica y procesamiento de hortalizas en la fase poscosecha, podría incrementar su vida de anaquel diferenciando el producto fortaleciendo su competitividad y la posibilidad de negociar un mejor precio en el mercado.

Así mismo (Marin et al., 2015) "Sistema web de bajo costo para monitorear y controlar un invernadero agrícola en Chile" en donde se ha desarrollado un sistema web de bajo costo que permite monitorear y controlar un invernadero. El monitoreo se realiza mediante la captura de variables climatológicas, dentro del invernadero, con sensores y microcontroladores instalados en su interior, cuyos datos son observados por medio de una aplicación web desde internet. Todo esto es posible gracias a la integración de un protocolo que permite realizar la comunicación entre el usuario y los dispositivos electrónicos implantados dentro del medio ambiente que se monitorea desde internet en tiempo real.

Por otro lado (Camacho et al., 2015) en su estudio "Caracterización de productores de hortalizas orgánicas distribuidas en la gran área metropolitana (GAM), en COSTA RICA" se identificaron tres tipos de productores caracterizados por la experiencia, cantidad de tierra entre otras. Adicional establecen que la producción de hortalizas orgánicas es un mercado en crecimiento, que requiere apoyo externo en forma de créditos y asistencia técnica para consolidarse, e incluso compensaciones por los servicios ambientales que produce; de cumplirse estas condiciones se podrá asistir en los próximos años a un crecimiento importante del sector.

A nivel regional se revisa la tesis desarrollada por (Montaña, 2016) titulada "Estudio de mercado para los productos Hortícolas del programa de agricultura familiar en el municipio de Duitama" - Boyacá en donde se menciona que los productores del Programa de Agricultura Familiar tienen explotaciones microfundista, de 
pequeña escala, con áreas muy pequeñas que apenas llegan hasta 600 Mts cuadrados, con características de economía campesina donde el $25 \%$ se destina al autoconsumo de las familias y el restante se comercializa en el mercado verde y mercados informales.

Es importante relacionar lo trabajado por (Ochoa, 2016) en su trabajo "Diseño de un software para asociaciones de productores frutícolas en la provincia del Tundama" en donde menciona que con el planteamiento de un software agrícola, enfocado hacia el sector frutícola, se formula un instrumento que contribuye al uso de las nuevas tecnologías, en beneficio de establecer parámetros que encaminen las pequeñas asociaciones, en dirección a la eficiencia y eficacia organizacional, ya que la implementación de sistemas informáticos, articulados con las labores productivas y administrativas, les permitirá a este tipo de organizaciones soportar la información pertinente en los procesos de, planificación dirección, organización y control

.Del mismo modo (Gutiérrez et al., 2013) en su artículo "Factibilidad de una comercializadora hortícola de economía solidaria en el Distrito de Riego del Alto Chicamocha" en Duitama - Boyacá enfocan el estudio como un aporte a la solución de uno de los problemas de los productores hortícolas del Distrito de Riego del Alto Chicamocha (Duitama, Colombia), consistente en la carencia de una organización empresarial que comercialice los productos en mejores condiciones de mercado. De acuerdo con el resultado, se hace necesario la organización de una empresa de tipo solidario cuya ubicación sea la ciudad de Duitama, donde los productores se asocien desde la producción hasta la comercialización para lograr la regulación de precios, la disminución de intermediarios y la obtención de mejores ingresos, al tiempo que desarrollen procesos productivos de acuerdo con las necesidades del consumidor, adelantando labores de poscosecha como adecuación y empaque.

\section{Metodología}

La metodología de investigación a emplear es el enfoque mixto ya que para desarrollar los objetivos de la investigación se hizo un análisis de documentos en bases de datos y la aplicación de encuestas y análisis de datos numéricos, por esta razón se hace necesario la combinación del enfoque cualitativo y cuantitativo con el fin de triangular la información y cumplir con el objetivo general de la investigación.

\subsection{Método Cuantitativo - exploratorio}

Según (Hernandez Sampieri, Fernandez Collado, \& Baptista Lucio, 2006) Los estudios exploratorios se realizan cuando el objetivo es examinar un tema o problema de investigación poco estudiado, del cual se tienen muchas dudas o no se ha abordado antes. Es decir, cuando la revisión de la literatura reveló que tan sólo hay guías no investigadas e ideas vagamente relacionadas con el problema de estudio, o bien, si deseamos indagar sobre temas y áreas desde nuevas perspectivas.

\subsection{Método cuantitativo - Encuesta estructurada (cuestionario)}

La técnica a utilizar en el método cuantitativo es la encuesta estructurada, mediante el diseño de un cuestionario, se utiliza el programa Google formas con el cual se crea el cuestionario y se envía virtualmente utilizando el enlace proporcionado por el programa, mediante correo electrónico y redes sociales como Facebook, Whatssap y Messenger. Para la aplicación de las encuestas se saca un muestra representativa de la población objetivo de la ciudad de sogamoso asi:

Público objetivo: Población que se encuentra entre los 18 a los 28 años, 29 a los 59 años. 
Tabla 1

Muestreo y tamaño de la muestra:

\begin{tabular}{|c|c|c|c|c|}
\hline \multirow{2}{*}{ Nivel de confianza } & Error de Muestreo & Tamaño de la Población & Probabilidad de éxito & Probabilidad de fracaso \\
\hline & $5 \%$ & 63.825 & $60 \%$ & $40 \%$ \\
\hline
\end{tabular}

Fuente. Autores (2020)

Aplicación de la Formula:

$$
\begin{aligned}
& n=\frac{N \times Z_{a}{ }^{2} \times p \times q}{d^{2} \times(N-1)+Z_{a}{ }^{2} \times p \times q} \\
& \mathrm{~N}=\frac{63825 \times 1.96 \wedge 2 \times 0.6 \times 0.4}{0.05 \wedge 2 \times(63825-1)+1.96 \wedge 2 \times 0.6 \times 0.4}=366.6
\end{aligned}
$$

El tamaño de la muestra aplicado la fórmula es de 366 encuestas

La encuesta es resuelta por 18 productores, esto debido a la contingencia de salubridad pública que se esta viviendo.

\section{Resultados}

\subsection{La población y sus características}

\section{Figura 1}

Municipio de Sogamoso

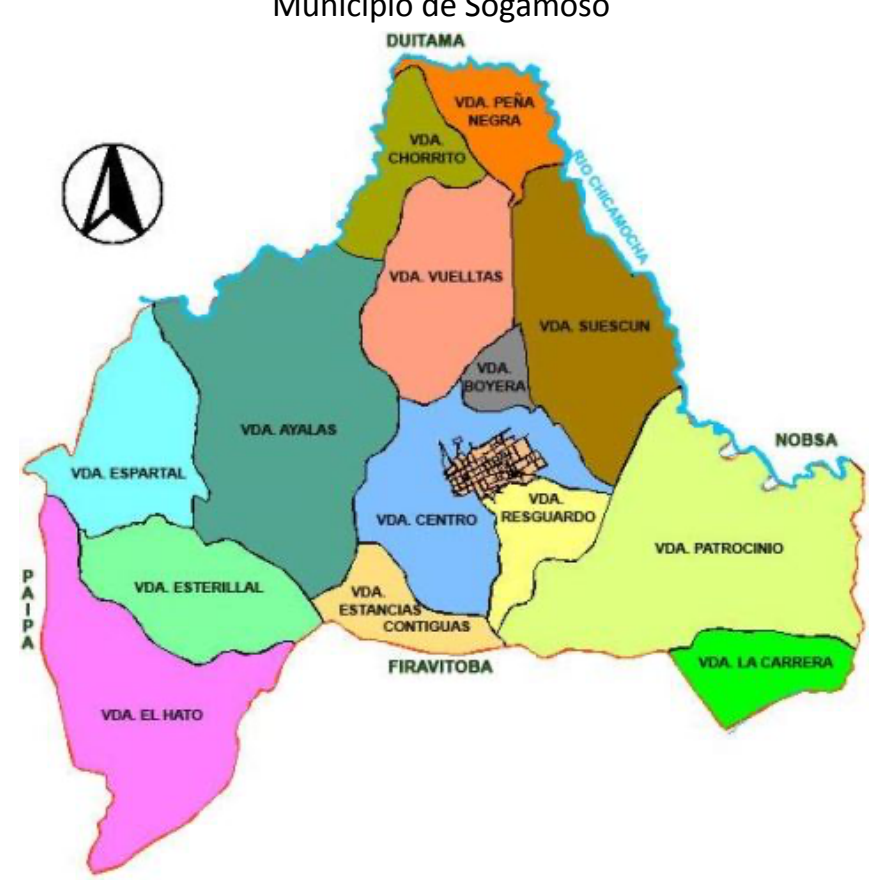

Fuente: boyaca.gov.co 
Ubicado al nordeste del Departamento de Boyacá, con una extensión de 3.407 kilómetros cuadrados, que corresponden al $14.4 \%$ del área total de Boyacá. Limita al Norte con las provincias de Tundama y Valderrama, al Sur con parte de la Provincia de Lengupá y con el Departamento de Casanare; por el Oriente, con parte de la Provincia de Valderrama, con Casanare y cierra por el Occidente con la Provincia del Norte

Población y sus características. La población de productores del Municipio de Sogamoso, Departamento de Boyacá en su mayoría son hombres cabeza de hogar, entre edades de 20 a 35 años un $66 \%$ de la muestra existe un $22 \%$ de productores escalonados como adultos mayores dependientes económicamente de la producción hortícola.

Se realiza una caracterización de los productores hortícolas de la provincia del Sugamuxi, posteriormente se realiza la propuesta de asociatividad, tomando como referencia los datos arrojados por el instrumento anteriormente mencionado.

\subsection{Caracterización productores hortícolas Municipio de Sogamoso.}

Población y sus características. La población de productores del Municipio de Sogamoso, Departamento de Boyacá en su mayoría son hombres cabeza de hogar, entre edades de 20 a 35 años un 66\% de la muestra existe un $22 \%$ de productores escalonados como adultos mayores dependientes económicamente de la producción hortícola.

Para el desarrollo de este apartado se implementó un instrumento tipo encuesta semiestructurada la cual fue incorporada al programa de google form, debió a la situación de salud que se está viviendo actualmente, se crearon las gráficas para las diferentes preguntas y posteriormente se hace el respectivo análisis.

Adicional a esto se realiza una visita decampo a los productores donde se diligenciaron el cuestionario como se muestra en las siguientes fotografías.

\section{Figura 1}

Finca de Producción de Hortalizas en Sogamoso

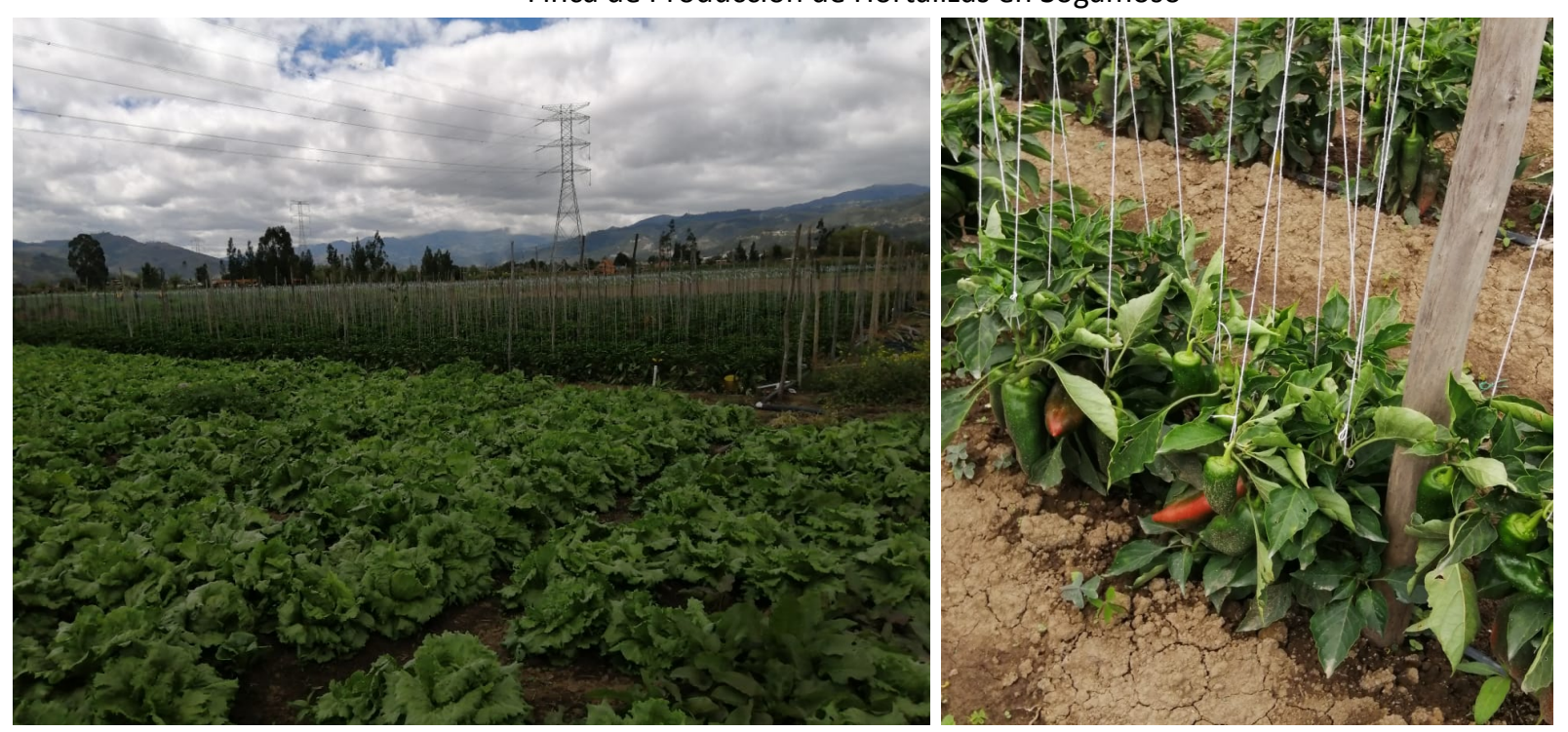

Fuente: (Autor, 2020) 


\subsection{Ficha socieconomica}

La ficha socioeconómica es diligenciada por 18 productores, debido a contingencia de salud que se está viviendo la muestra total no fue posible dado a que no todos los productores cuentas con los elementos tecnológicos dispuestos para ello, para esto se resaltan las preguntas más significativas acorde a la investigación.

Como resultados de la implementación de la encuesta se realizan las siguientes preguntas como se evidencia en la siguiente tabla.

\section{Tabla 1}

Ficha socioeconómica.

\begin{tabular}{ll} 
Ítem & Pregunta \\
\cline { 1 - 3 } económicos & ¿Cuantas personas componen su familia? \\
& ¿En su hogar han realizado la encuesta del sisben? \\
& Disponibilidad de Servicios Públicos \\
& ¿'Disponibilidad de vías de acceso? \\
& ¿Cuántos jornales son utilizados en su predio por \\
& mes? \\
& ¿Producto? \\
& ¿Variedad de Producto? \\
& ¿Volumen producido por Unidad? \\
& ¿Cantidad producido por Unidad? \\
& ¿Volumen producido para la venta Unidad? \\
& ¿Cantidad de Volumen producido para la venta \\
& Unidad? \\
& ¿Precio mínimo por Unidad Precio? \\
& ¿Precio máximo por Unidad Precio? \\
& ¿Uso de Crédito actual? \\
& ¿Sus ingresos mensuales se encuentran? \\
& ¿Ha recibido capacitación? \\
& ¿De cuál entidad? \\
& ¿Realiza procesos de innovación? \\
& ¿Pertenece a asociaciones cooperativas o \\
& agremiaciones? \\
& Si pertenece a asociaciones cooperativas o \\
& agremiaciones, diligencie la información \\
& Nombre de la organización \\
& Beneficio recibido \\
& Periodicidad de asistencia a reuniones \\
& Razón para no pertenecer a alguna asociación, \\
& cooperativa o agremiación \\
& ¿Entidades a las que no se esté asociado pero que \\
& presten apoyo? \\
& ¿Asistencia Técnica? \\
& ¿Información de Insumos Agrícolas? \\
\hline Aspectos & \\
Asociativos & \\
\hline &
\end{tabular}




\begin{tabular}{ll}
\hline Aspectos & ¿Programa de residuos? \\
ambientales & ¿Tipos de Programas de Residuos? \\
& .ंAnálisis de suelos? \\
& ¿Control de Arvenses? \\
& ¿Control de Enfermedades? \\
& ¿BPA? \\
& ¿Tiene otro tipo de cultivos? \\
& ¿Hace rotación de cultivos? \\
\hline
\end{tabular}

\subsection{Desarrollo del instrumento (ficha socioeconómica) implementado}

\section{Acercamiento a campo}

Este acercamiento de campo se realiza con autorización de la asociación, presentando el proyecto de investigación a los productores Hortícolas, del municipio de Sogamoso, con el fin de dar viabilidad con el desarrollo, posteriormente se hace un reunión con la comunidad informando sobre el proyecto y extendiendo la invitación; posteriormente se realiza el proceso de inscripción y conformación de los grupos de trabajo, este proceso con el ánimo de desarrollar los objetivos propuestos para la investigación.

\section{Formulario productores hortícolas sogamoso}

Se activó un Formulario de cuarenta (40) preguntas, dando respuesta a ellas dieciocho (18) productores específicamente en temas como el avance con respecto a las cosechas, el estado de las fincas y los beneficios que recibían.

A continuación, se presenta el análisis a cada una de las preguntas formuladas a los productores de hortícolas en Sogamoso.

\section{Aspectos Económicos}

\section{¿Cuantas personas componen su familia?}

Gráfico 1

Composición de Familia

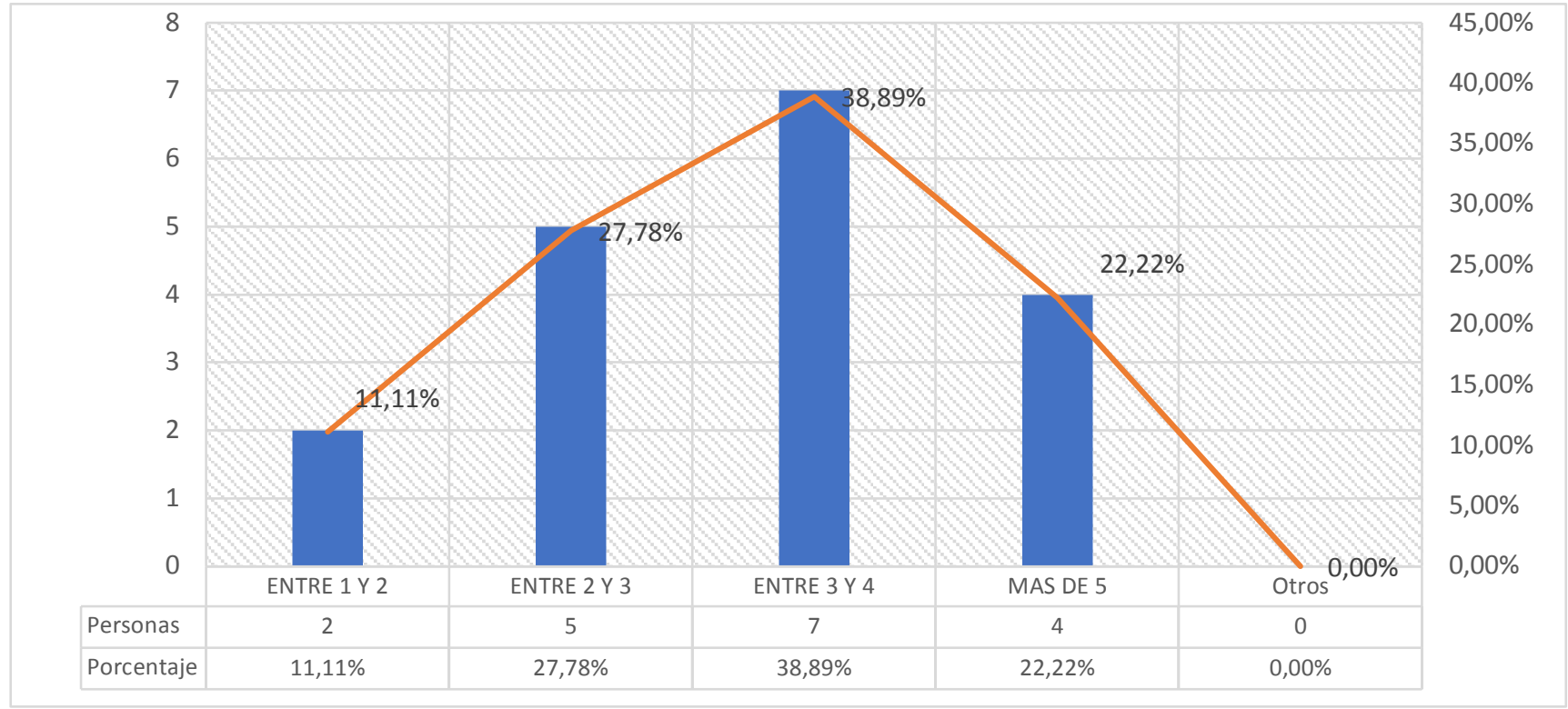

Fuente: (Autora, 2020)

Donde se puede evidenciar que esta población la composición familiar oscila entre tres y cuatro miembros del hogar, los cuales se dedican a las labores del sector agropecuario. 


\section{¿Sus ingresos mensuales se encuentran?}

Gráfico 2

Ingresos mensuales

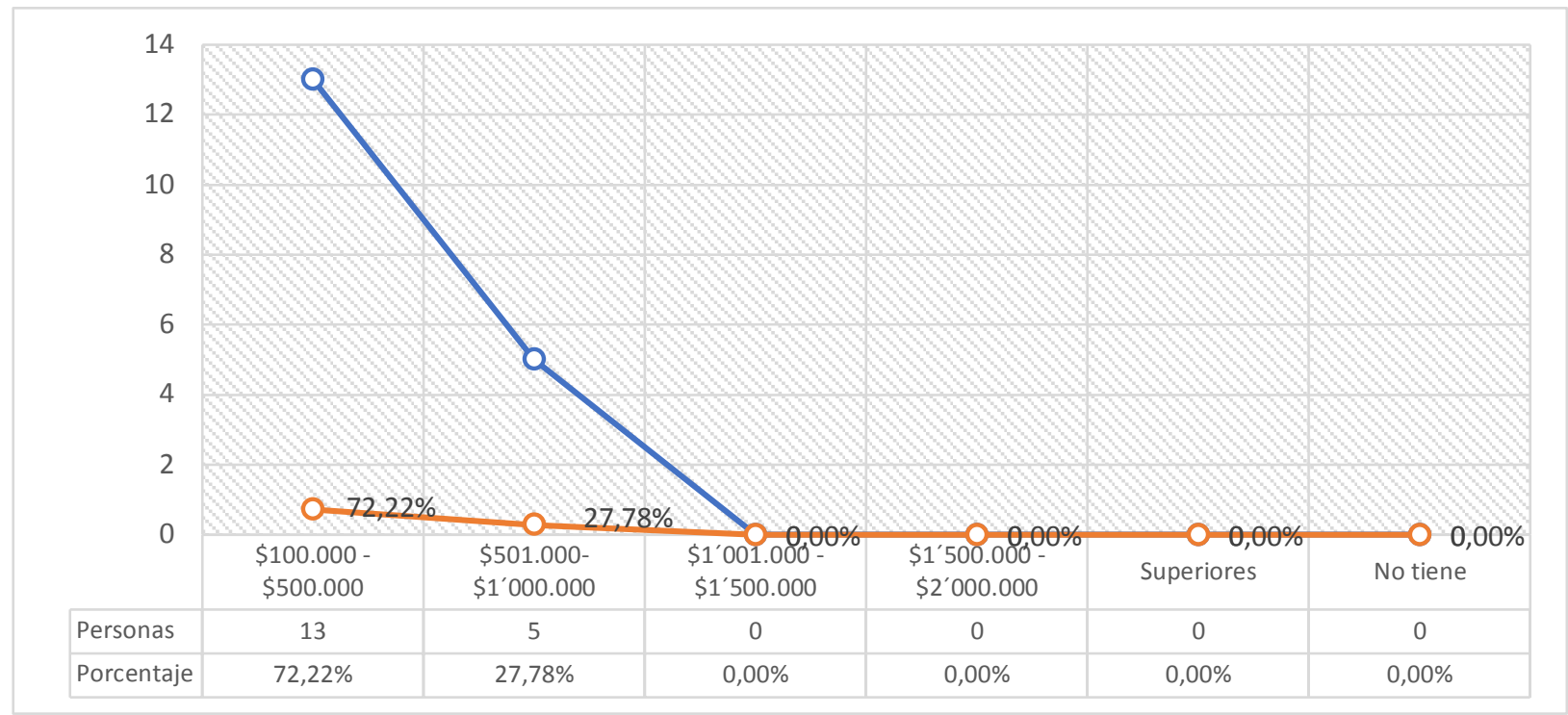

Fuente: (Autora, 2020)

Como muestra el grafico el rango de ingresos que percibe esta población está entre 1,5 Salarios Mínimos Legales Vigentes, por los cuales se refleja el bajo nivel de las condiciones económicas de estos productores.

\section{Disponibilidad de Servicios Públicos}

Gráfico 3

Disponibilidad de Servicios Públicos

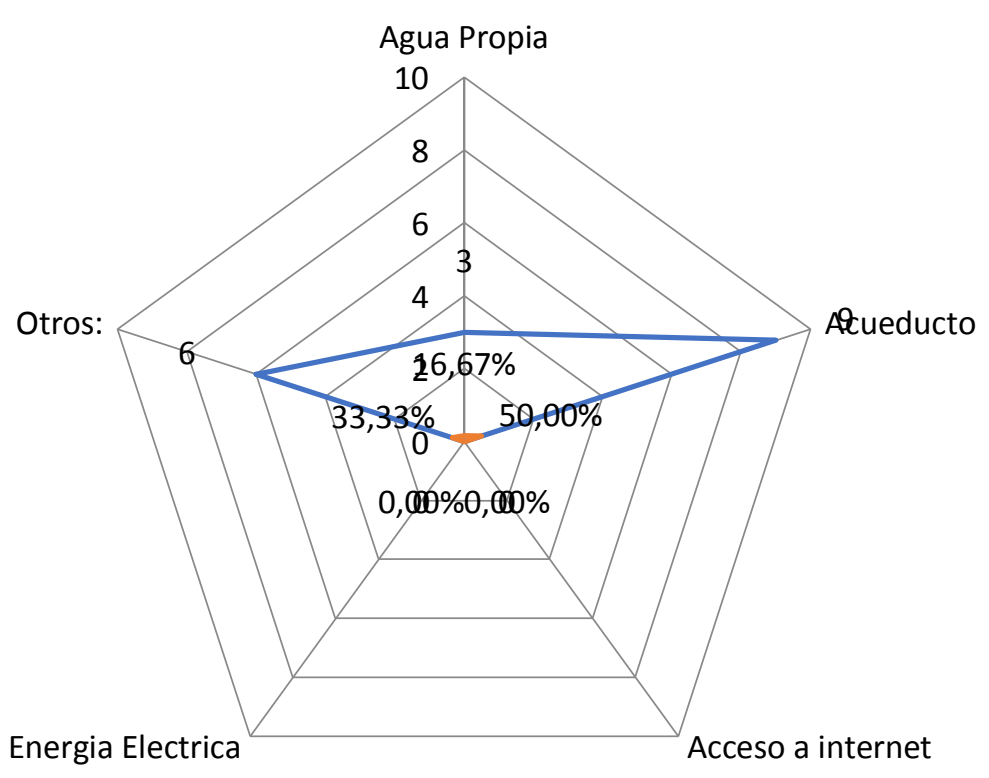

Fuente: (Autora, 2020) 
En esta ilustración se puede evidencias que los productores cuentan con acceso a servicios públicos, sin embargo, la falencia en el servicio eléctrico tiene un impacto negativo grande, dado las condiciones geográficas para poder suministrar esta importante asistencia a la comunidad.

\section{¿Uso de Crédito actual?}

\section{Gráfico 4}

Uso de crédito actual

\begin{tabular}{|c|c|c|c|c|}
\hline 14 & $1266,67 \%$ & & & \multirow{2}{*}{$70,00 \%$} \\
\hline 12 & $12 \sqrt{-1}$ & & 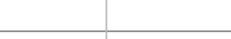 & \\
\hline 10 & & & & $\begin{array}{l}60,00 \% \\
50,00 \%\end{array}$ \\
\hline 8 & & & & $40,00 \%$ \\
\hline 6 & & $\sqrt[5]{27}$ & & $30,00 \%$ \\
\hline 4 & & & & $20,00 \%$ \\
\hline 2 & & & & $10,00 \%$ \\
\hline 0 & & & & $0,00 \%$ \\
\hline & Si & No & No respondió & \\
\hline Personas & 12 & 5 & 1 & \\
\hline Porcentajes & $66,67 \%$ & $27,78 \%$ & $5,56 \%$ & \\
\hline
\end{tabular}

Fuente: (Autora, 2020)

Como lo muestra la gráfica el $66 \%$ de los productores encuestados presentan algún tipo de crédito actualmente, especialmente en las entidades designadas por el gobierno nacional para el sector agropecuario.

Con la presentación de esta información se puede concluir que, aunque este sector económico es importante para la región, el número de ingresos es muy bajo para el núcleo familiar que poseen, por tal razón se evidencian algunas carencias básicas como acceso a servicios públicos que posee esta comunidad.

\section{Aspecto del producto}

\section{¿Producto?}

\section{Gráfico 5}

Producto cosechado

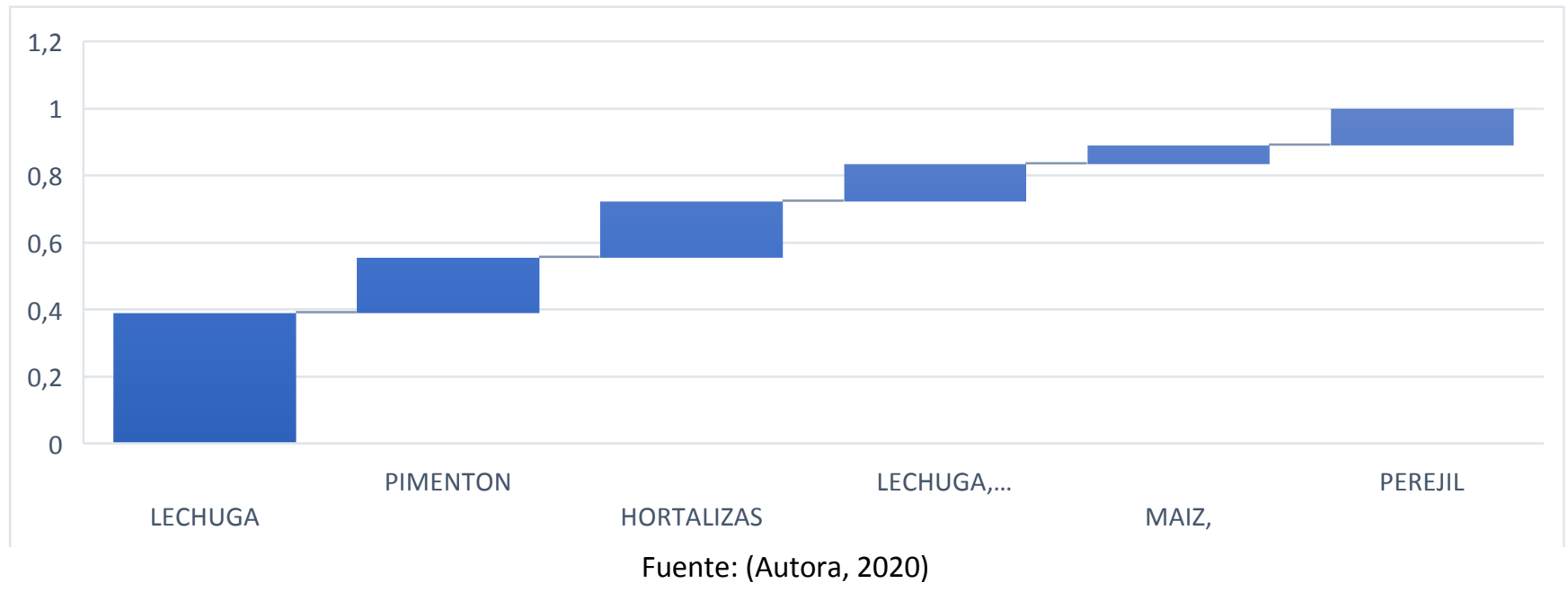

Gracias a la variedad climática que se presenta en esta región, los productores hortícolas del municipio de Sogamoso se enfocan relevantemente al cultivo de lechuga; siendo este el principal producto que estos 
productores ofrecen a la región, especialmente dado la cercanía a las plazas mayoristas de mercado que distribuyen los productos para gran parte del departamento de Boyacá.

\section{¿Variedad de Producto?}

\section{Gráfico 6}

Variedad de Producto

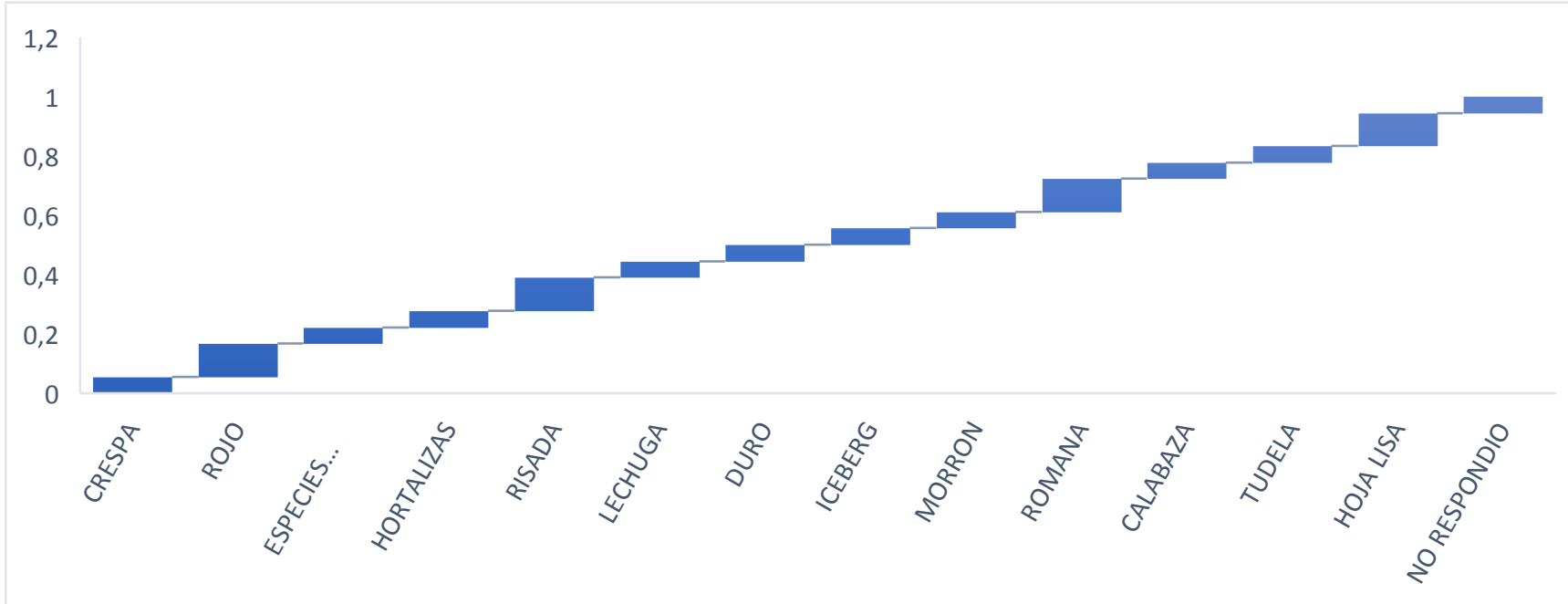

Fuente: (Autora, 2020)

Los productores manifiestan la variedad de lechuga siembran en las fincas, haciendo énfasis a la de hoja lisa, esta tiene mayor impacto debido a las exigencias que los almacenes de cadena tienen para poder suministrar.

\section{Pregunta $\mathbf{N}^{\circ} 11$. ¿Volumen producido para la venta Unidad?}

\section{Gráfico 7}

Volumen producido para la venta Unidad

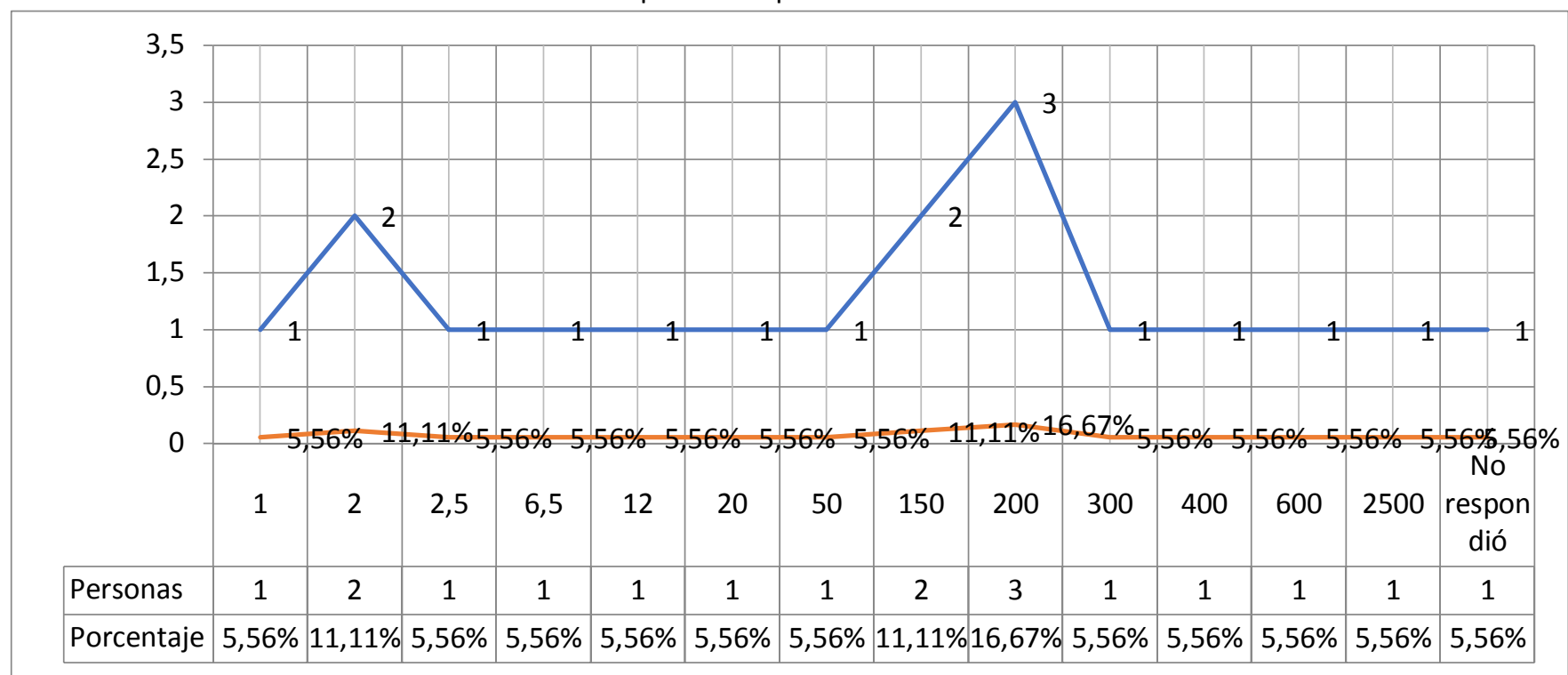

Fuente: (Autora, 2020)

Obtenidas las distintas cosechas, se indagó sobre el volumen producido para la venta. No hubo una respuesta que destacara sobre el resto, salvo aquella donde tres (3) de los productores consultados, es decir 16,67\%, coincidieron con un volumen de 200 unidades. 


\section{Gráfico 8}

Precio mínimo por Unidad Precio

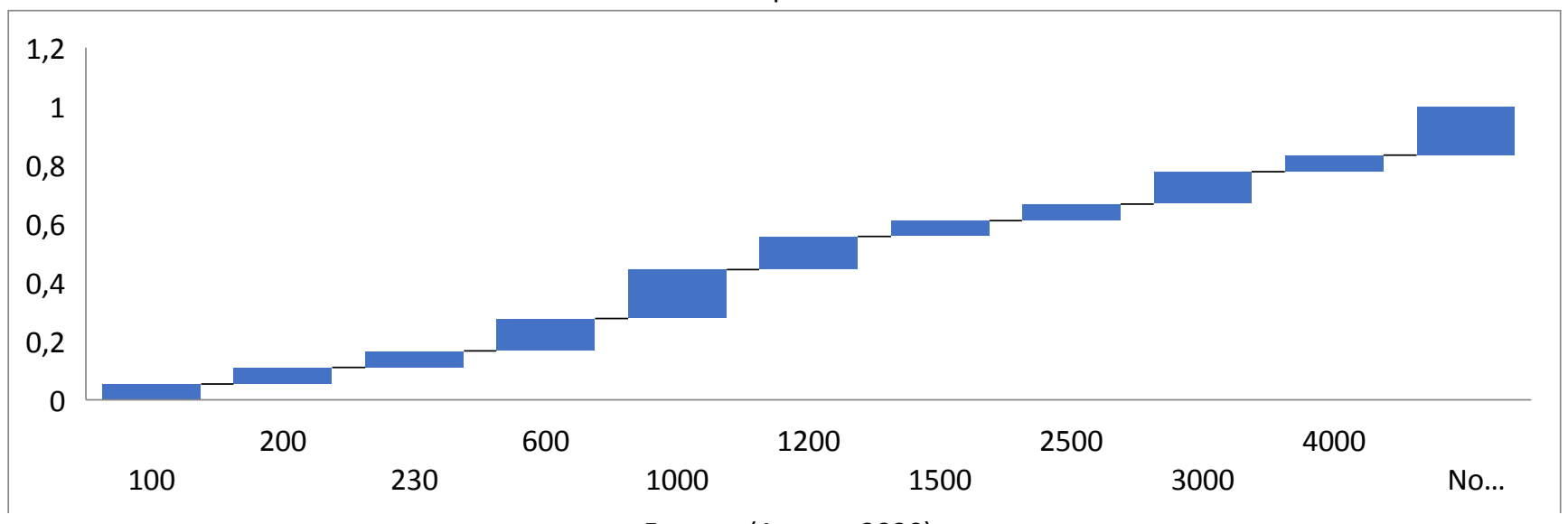

Fuente: (Autora, 2020)

Una vez obtenidas las distintas cosechas por los productores, se les preguntó por el precio mínimo por unidad de precio. Esto dependía directamente de la producción de cada una de las fincas. En este caso, los productores ofrecieron sus diversas respuestas, donde el precio de venta oscila entre 100 a 4000 pesos, siendo el más representativo los productos cuyo valor es de 1.000 , siendo muy bajo respecto a los costos de producción que se implementas en cada cosecha.

Se puede deducir que los productores hortícolas de la ciudad de Sogamoso son fuertes en la comercialización de productos especialmente las hortalizas (Lechuga) debido a ubicación geográfica del municipio y la cercanía con otras localidades del departamento.

\section{Aspectos asociativos}

\section{¿Ha recibido capacitación?}

Gráfico 9

Recepción de Capacitación

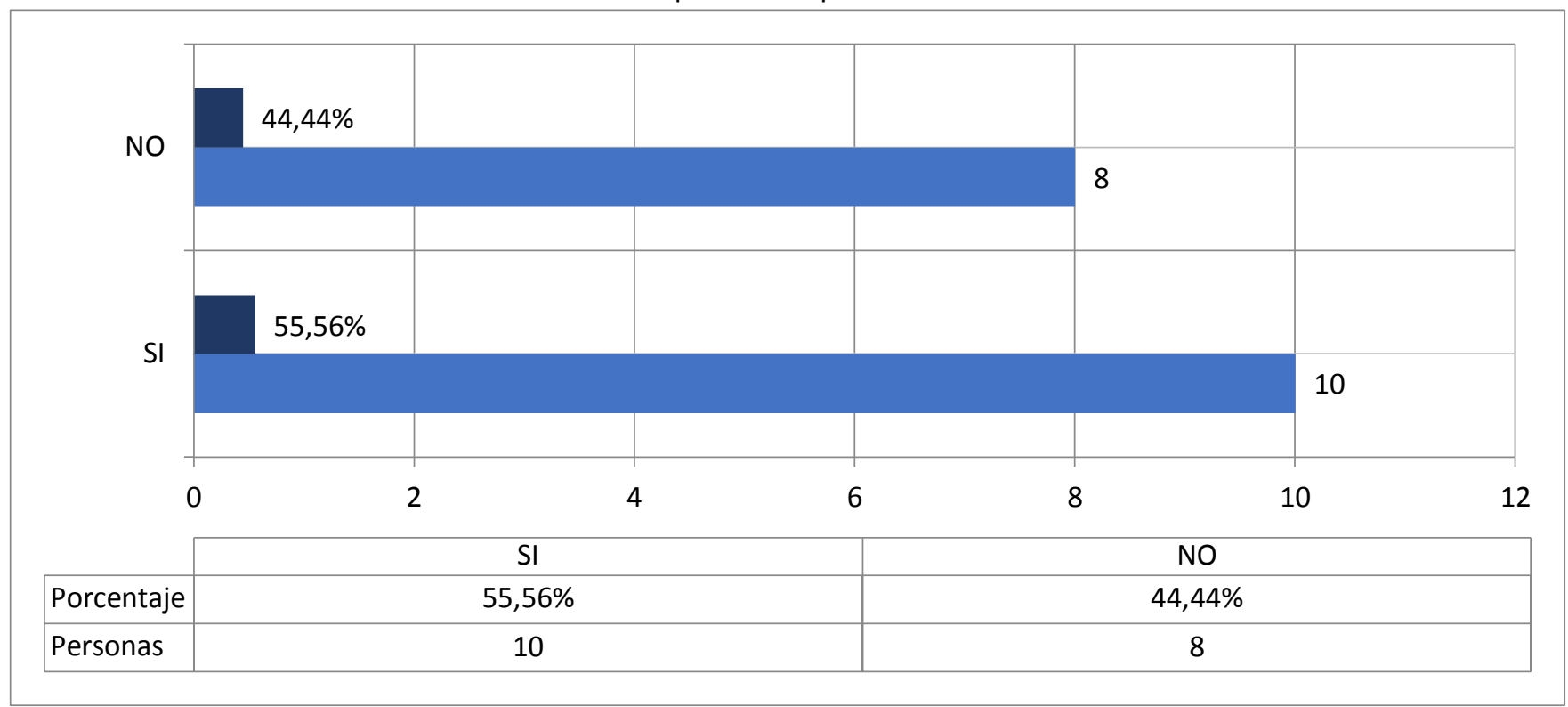

Fuente: (Autora, 2020) 
Como se ve en el grafico 55,56\% si han recibido algún tipo de capacitación en temas relacionados con las labores de siembra y procesos culturales.

\section{¿De cuál entidad?}

Gráfico 10

Entidad de Capacitación

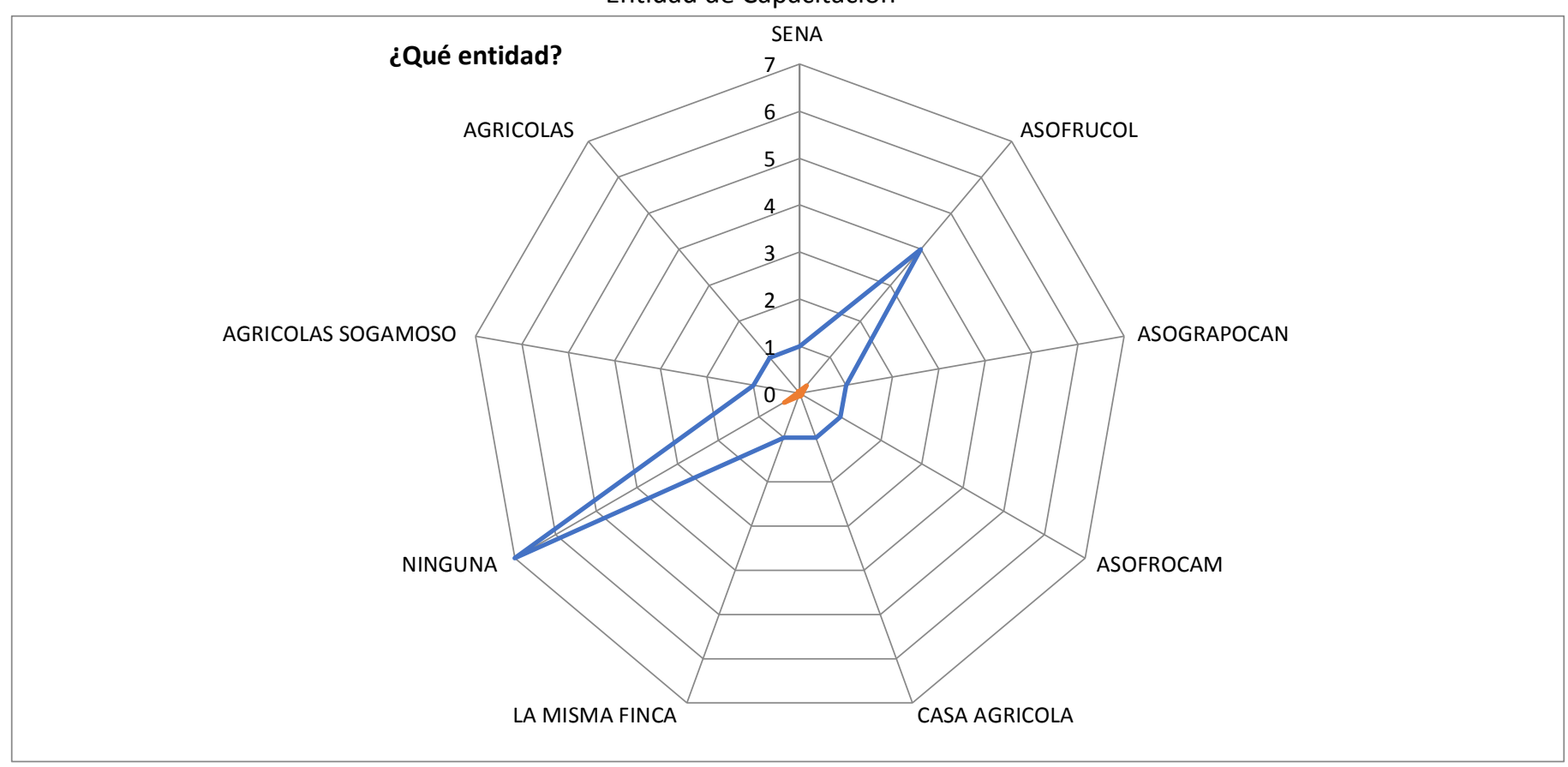

Fuente: (Autora, 2020)

Donde se evidencia que la entidad fuerte en capacitaciones para los productores de esta región es Asofrucol, pero se muestra que hay una población fuerte que aún no se vinculado a estos procesos de aprendizaje.

\section{¿Pertenece a asociaciones cooperativas o agremiaciones?}

Gráfico 11

Pertenencia a Asociaciones

Cooperativas o Agremiaciones

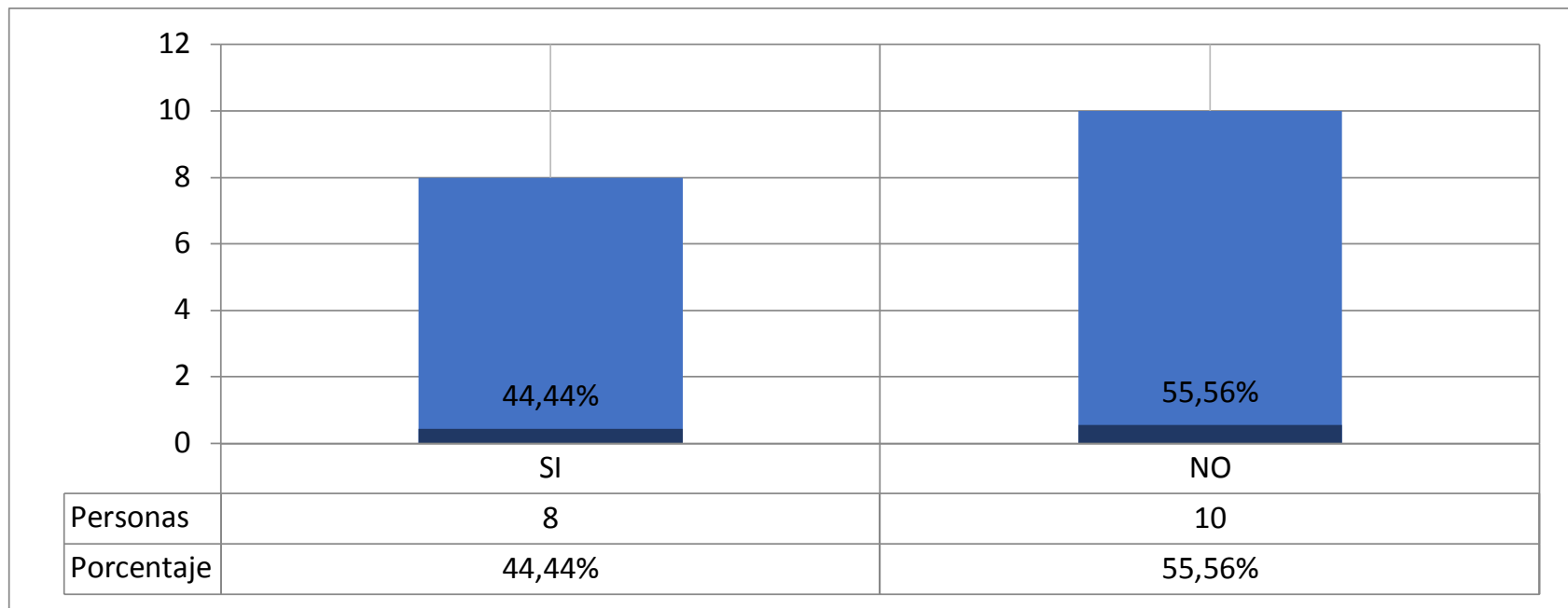

Fuente: (Autora, 2020) 
Donde se puede evidenciar que el $55,6 \%$ no pertenece a ningún tipo de asociación, reflejando esto la baja en cuanto a la comercialización de los productos.

\section{Nombre de la organización}

Se les pidió a los encuestados el nombre de la organización para la cual su cosecha es manejada. El 27,78\% de los consultados, es decir, cinc (5) de ellos, nombraron a Asofrucol, destacándose entre las respuestas válidas a esta pregunta. Vale destacar que cinco (5) no quisieron responder (27,78\%) y dos (2) manifestaron que no conocían de ninguna entidad (11,11\%). Los resultados pueden observarse en el Gráfico 9 que se muestra a continuación:

Gráfico 12

Nombre de la Organización

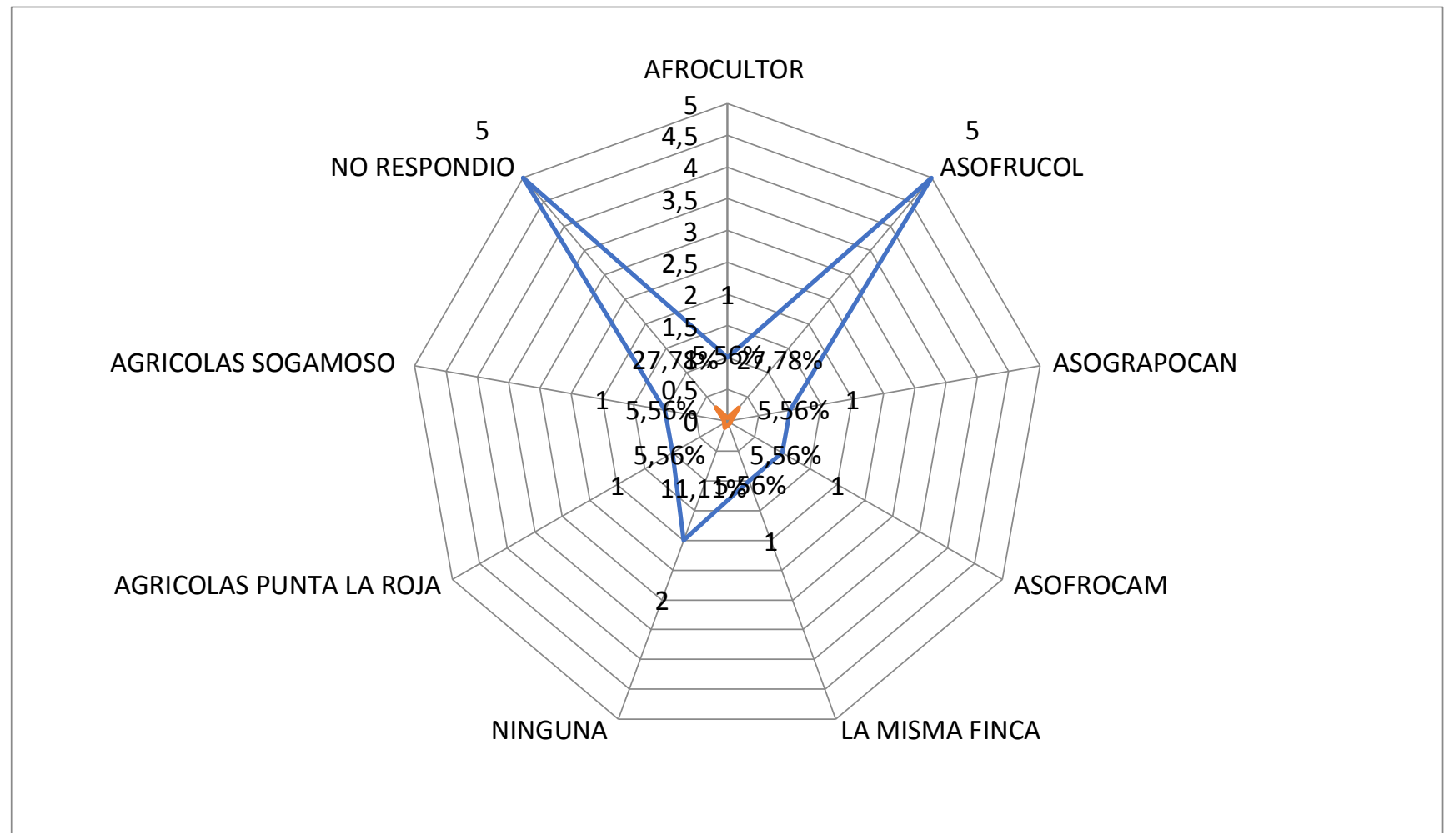

Fuente: (Autora, 2020)

Siendo asofrucol la entidad en la cual los productores que manifestaron la asociación se encuentran integrados.

\section{Beneficio recibido}

De los productores se solicitó información de cuáles son los beneficios obtenidos en Sogamoso. Solo respondieron doce (12) de ellos, donde diez (10), el 55,56\% de la muestra, manifestó que recibía Capacitación. Los otros dos dijeron que obtenían como beneficio la recreación o la participación en la toma de decisiones de la colectividad. Los resultados se pueden observar en el Gráfico 22, que se muestra a continuación: 
Gráfico 12

Beneficio recibido

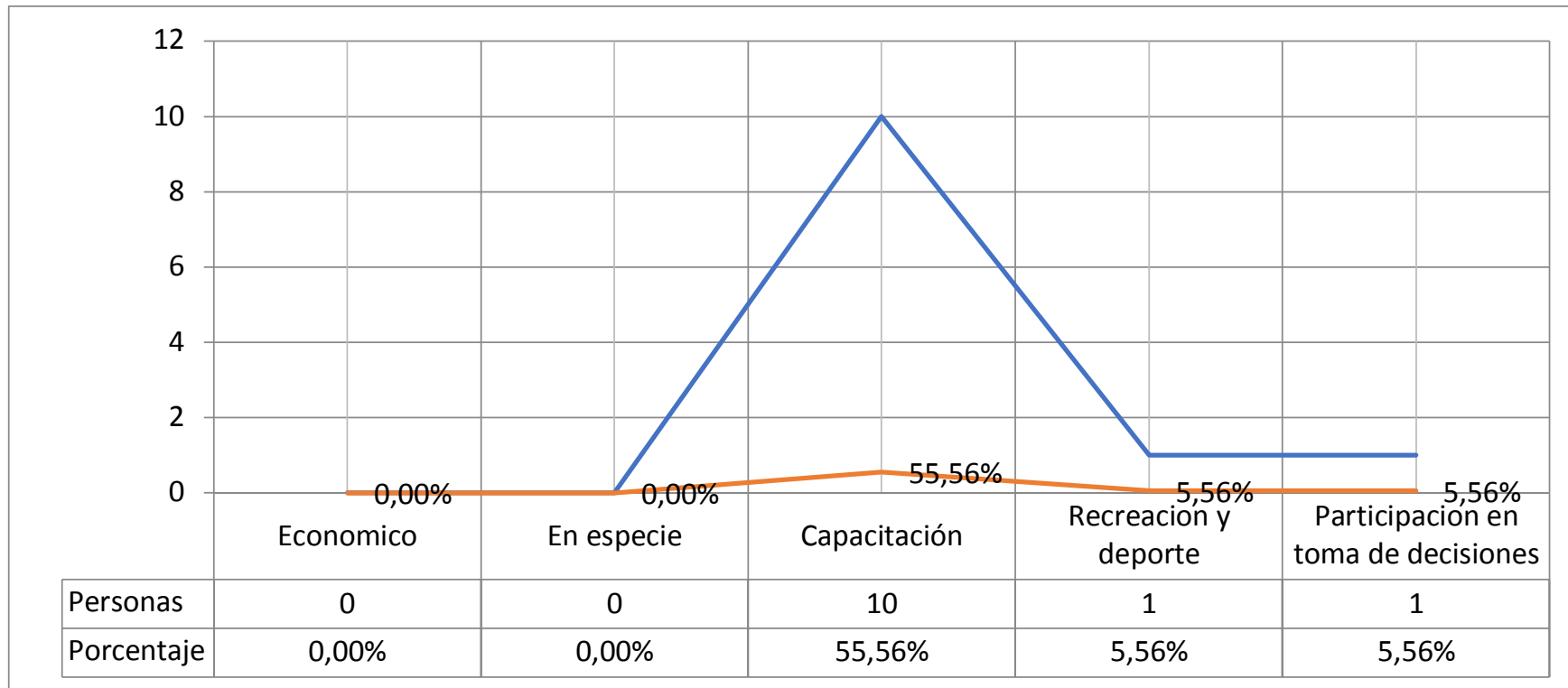

Fuente: (Autora, 2020)

En el cual el beneficio que mayor a obtenido es la capacitación en temáticas relacionada con el proceso de producción, recolección y comercialización.

Pregunta $\mathbf{N}^{\circ}$ 24. Razón para no pertenecer a alguna asociación, cooperativa o agremiación

\section{Gráfico 13}

Razón de no pertenencia a alguna asociación, cooperativa o agremiación

\begin{tabular}{|c|c|c|c|c|c|}
\hline \multirow[t]{2}{*}{16} & & & & & $90,00 \%$ \\
\hline & 14 & & & & $80,00 \%$ \\
\hline 12 & & & & & $70,00 \%$ \\
\hline 10 & & & & & $60,00 \%$ \\
\hline 8 & & & & & $50,00 \%$ \\
\hline 6 & & & & & $40,00 \%$ \\
\hline 1 & & & & & $30,00 \%$ \\
\hline & & ( & 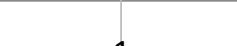 & 2 & $20,00 \%$ \\
\hline 2 & & & & & $10,00 \%$ \\
\hline 0 & Desconocimiento & Falta de interes & Falta de tiempo & Falta de oportunidad & $0,00 \%$ \\
\hline Personajes & 14 & 1 & 1 & 2 & \\
\hline Porcentaje & $77,78 \%$ & $5,56 \%$ & $5,56 \%$ & $11,11 \%$ & \\
\hline
\end{tabular}

Fuente: (Autora, 2020)

Los productores manifiestan que la razón por la cual no pertenecen a ninguna asociación es por el desconocimiento, ya que, por el desarrollo del proceso del campo, la ubicación de las fincas y acceso a medios de comunicación, no es fácil poder tener contacto con las agremiaciones y entidades del sector. 


\section{Aspectos ambientales}

\section{Pregunta $\mathbf{N}^{\circ} 28$. ¿Programa de residuos?}

En la pregunta 28 se le solicitó información a los encuestados de si tenía programa de residuos en sus fincas. Catorce (14) de ellos, más de las tres cuartes partes (77,78\%), a firmaba que sí tenían, el restante dijo no tenerlo. Los resultados pueden ser apreciados en el Gráfico 28 que se muestra a continuación:\}

Gráfico 14

Programa de Residuos

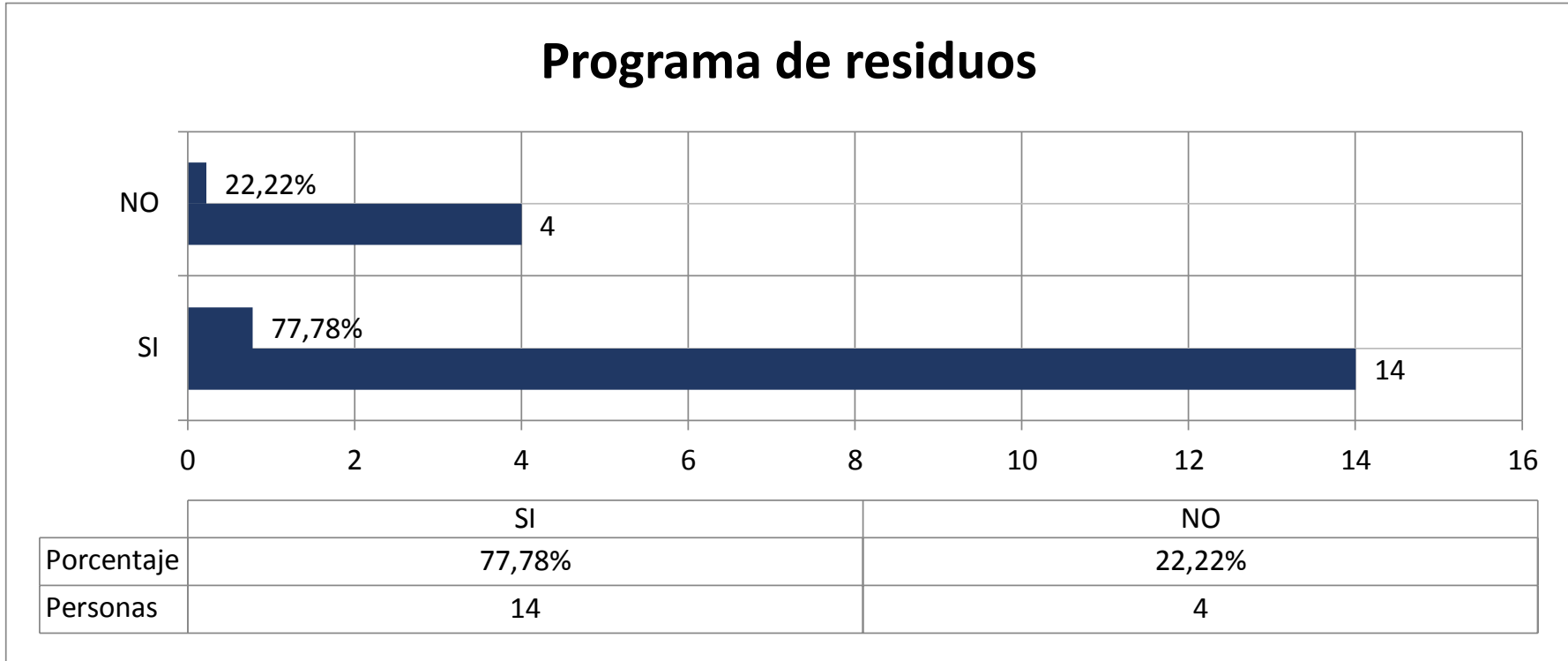

Fuente: (Autora, 2020)

Gráfico 15

Tipos de Programas de residuos

\section{Tipo de Programa de residuos}

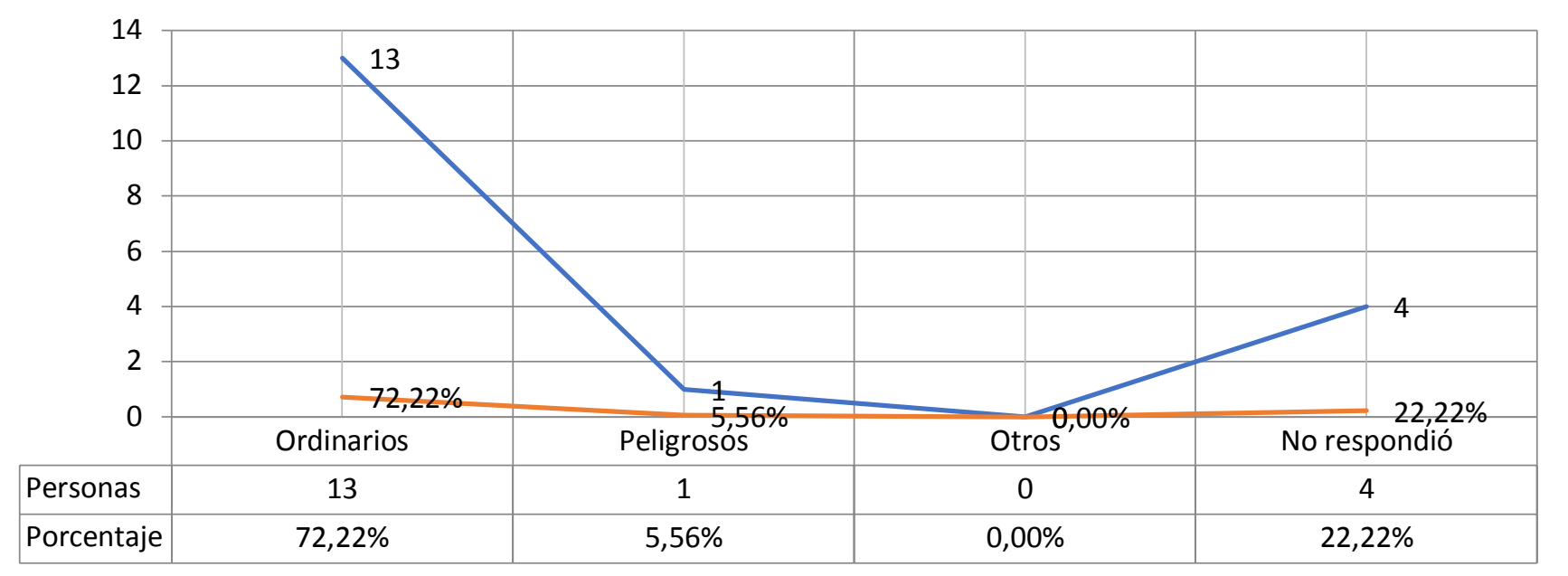

Fuente: (Autora, 2020) 
Teniendo en cuenta las exigencias planteadas por el gobierno nacional y para poder ofrecer los productos a entidades competentes, los productores manejan programas de residuos sólidos, especialmente los ordinarios.

Una vez identificadas las necesidades de los productores tomadas de la caracterización se toma como última fase de la investigación la creación de la propuesta de asociatividad; con el fin de presentarla a la comunidad para que esta a su vez se implementada en un corto plazo.

\section{Propuesta asociativa de cadenas productivas}

\section{Definiciones}

El concepto de cadenas productivas según la (Comisión Económica para América Latina y el Caribe, 2001) “implica la concentración sectorial y/o geográfica de empresas que desempeñan a las mismas actividades estrechamente relacionadas entre sí (tanto hacia atrás como hacia delante) con importantes y acumulativas economías externas y posibilidad de llevar a cabo una acción conjunta en la búsqueda de la eficiencia colectiva"

Así mismo (Delia Rodriguez et al., 2016) mencionan que en este ámbito, las cadenas productivas, según la Corporación de Desarrollo de la Región de Los Andes y sus Filiales (CORPOANDES, 2013), son aquellas conformadas por una red de actores, en la cual los agentes que la conforman, centran sus actividades en la producción de un producto o servicio, de manera concatenada aportando cada actor un eslabón particular dentro del proceso productivo.

Del mismo modo (Cruz, 2015) establece que las cadenas productivas son "Interrelación de actores independientes que intervienen en una misma actividad desde el abasto de los insumos, la producción, la distribución y la comercialización, para llevar el producto al consumidor final".

\section{Características}

Las cadenas productivas cuentan con estructuras diferenciadas que tienen interacciones entre ellas y que aportan a la construcción de un objetivo común. Entre estas estructuras se encuentran los eslabones, los segmentos, los flujos y los entornos organizacional e institucional, con esta serie de elementos se construyen los modelos de la cadena productiva. (O. F. Castellanos et al., 2009)

La cadena productiva se caracteriza por ser secuencial, involucrar a dos o más sectores productivos y económicos, la interdependencia, el aporte de todos los eslabones y los beneficios equitativos según los recursos que tiene cada actor. En este enlace entre unidades productivas que relaciona las etapas de abastecimiento de insumos, transformación, distribución y comercialización de un bien o servicio específico los distintos eslabones efectúan acuerdos que condicionan sus vínculos y supeditan sus procesos técnicos y productivos, a fin de hacer competitivos los productos en los ámbitos nacional e internacional. (Organización de las Naciones Unidas para el Desarrollo Industrial \& ONUDI, 2004)

\section{Autores}

En el ámbito internacional los primeros acercamientos al concepto de cadena productiva, parten de las teorías de eslabonamientos propuestas por Albert Hirschman en 1958, definidos como "el conjunto de fuerzas que generan inversiones y que son accionadas cuando la capacidad productiva de los sectores que producen insumas para esa línea y/o que utilizan los productos de la misma es insuficiente afirma (O. Castellanos et al., 2001)

Por otro lado (Antúnez Saiz \& Ferrer Castañedo, 2016) citan a Gomes Castro y Valle Lima (2003) quienes afirman que las cadenas productivas constituyen conjuntos de actores sociales - grupos de actores sociales involucrados en los diferentes eslabones de una cadena productiva - interactivos, tales como sistemas productivos agropecuarios y agroforestales, proveedores de servicios e insumos, industrias de procesamiento y 
transformación, distribución y comercialización, además de consumidores finales del producto y subproductos de la cadena. Los actores sociales de cada cadena productiva pueden presentar un comportamiento cooperativo o conflictivo entre sí, en situaciones diversas.

\section{Fases para construir la propuesta}

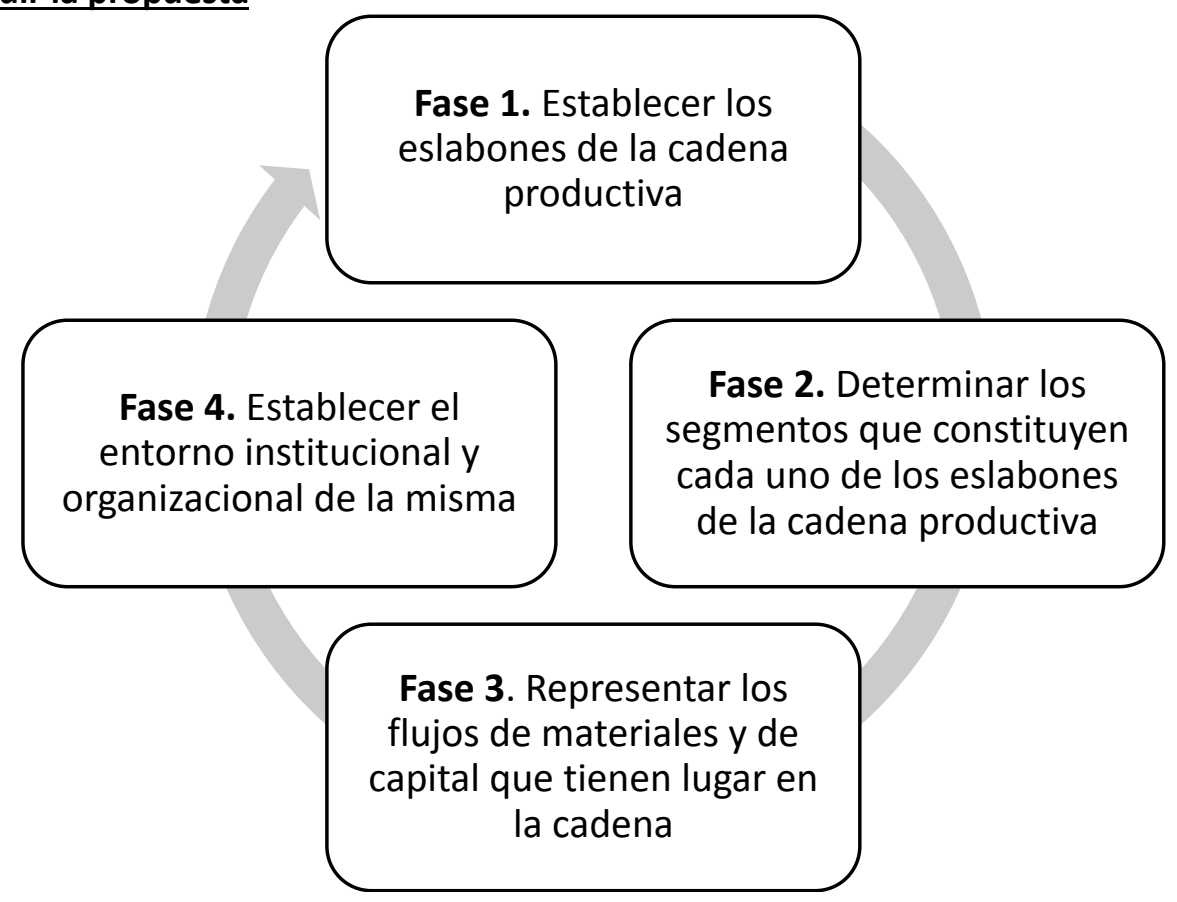

\section{Conclusiones}

Teniendo en cuenta las categorías planteadas para el desarrollo de la ficha socioeconómica, junto con los resultados obtenidos, se plantean las siguientes estrategias las cuales fueron socializadas con los productores del municipio de Sogamoso, con el ánimo de implementarlas a un mediano plazo tomando como eje fundamental el apoyo por parte de la academia, empresa y estado para mejorar el posicionamiento de estos productores.

Dentro de las estrategias económicas que se plantean es diseñar apoyo gubernamental por medio de la academia (Universidad y Sena) para lograr efectivamente la inclusión de estos productores para la consecución de recursos económicos que les ayude a participar en proyectos productivos acorde a los conocimientos por parte de la comunidad.

En cuanto a los productos se propone realizar campañas de sensibilización para los productores; con aras a la rotación con el fin de incluir nuevos productos en diferentes meses del año y así mismo mejorar la oferta y la demanda con el ánimo de posicionarlos con una buena cadena de comercialización.

El aspecto asociativo es fundamental para que el sector agropecuario crezca, en el caso de la población objeto de estudio es fundamental realizar estrategias asociativas, dar a conocer a los productores la importancia de incluirse en estas agremiaciones y romper paradigmas que manejan durante muchos años relacionados con este importante tema, mostrando las ventajas de la asociatividad especialmente en la fase de comercialización, enfatizando la necesidad de presentar los productos con una mejor imagen y manejo de poscosecha con el fin de ser más competitivos en el mercado y posicionar estos productos a nivel nacional.

\section{Bibliografía}

Acevedo, M., \& Buitrago, M. (2009). Asociatividad empresarial, crecimiento productivo e innovacion. Iles y confecciones en BogotáEl caso de las PYMES del sector text. En Universidad de la Salle (Vol. 2, Número 5). 
Agencia Presidencial de Cooperación. (2016). Asociatividad: Balance de las experiencias de cooperación internacional en Colombia 2010-2016.

Agronet. (2019). Agronet-Estadisticas Agropecuarias. https://www.agronet.gov.co/estadistica/Paginas/home.aspx

Antúnez Saiz, V. I., \& Ferrer Castañedo, M. (2016). El Enfoque de cadenas productivas y la planificación estratégica como herramientas para el desarrollo sostenible en Cuba. RIPS: Revista de Investigaciones Políticas y Sociológicas, 15(2). https://doi.org/10.15304/rips.15.2.3383

Arango, L., \& Martinez, C. (2007). Propuesta de un modelo de asociatividad aplicado a los restaurantes de la zona aledaña a la Pontificia Universidad Javeriana de Bogotá.

Arias, L., Portilla, L. M., \& Cataño, J. C. (2010). Modelo asociatividad para producción de piña deshidratada.

Arvizu, E., Mayett, Y., Martínez, J. L., Olivares, E., \& Flores, L. (2017). Análisis de producción y comercialización hortícola del estado de Puebla: Un enfoque de cadena de valor. Revista Mexicana de Ciencias Agrícolas, 6(4), 779. https://doi.org/10.29312/remexca.v6i4.618

Banco de España. (2019). Informe de economía Primer semestre de 2019. Boletin Económico 2019, 17.

Banco Mundial. (2019). Agricultura y alimentos.

Banrep. (2017). Coyuntura del sector agropecuario colombiano. Documento conyuntura Ganadera Colombiana, 86-92.

Camacho, M., Arauz, K., Barboza, N., Martínez, H., \& Arias, J. (2015). Caracterización De Productores De Hortalizas Orgánicas Distribuidas En La Gran Área Metropolitana (Gam), Costa Rica. Agronomia Costarricense, 39(2), 131-142.

Castellanos, O. F., Torres, L. M., \& Domínguez, K. P. (2009). Manual metodológico para la definición de agendas de investigación y desarrollo tecnológico en cadenas productivas agroindustriales. Universidad Nacional de Colombia.

Castellanos, O., Rojas, J., Villarraga, L., \& Ustate, E. (2001). Conceptualización y papel de la cadena productiva en un entorno de com petitividad. 18, 87-98.

Catellanos, O., Rojas, J., Villarraga, L., \& Ustate, E. (2010). Conceptualización y papel de la cadena productiva en un entorno de competitividad.

Comisión Económica para América Latina y el Caribe. (2001). Apertura económica y (des) encadenamientos productivos.

CONDÍA, S. N. (2016). PLAN DE DESARROLLO MUNICIPAL "SOGAMOSO INCLUYENTE" 2016 - 2019 (p. 306). https://sogamosoboyaca.micolombiadigital.gov.co/sites/sogamosoboyaca/content/files/000061/3036_pla ndesarrollomunicipalsogamosoincluyente.pdf

Corporación Colombia Internacional. (2006). Plan Nacional Horticola.

Cruz, B. (2015). Las cadenas productivas con impacto económico y social: El caso de los cítricos en Cuba. Economía y Desarrollo, 154(1), 105-117.

Enrique, C. (2002). El Salvador: La asociatividad empresarial entre pymes. (p. 147). Iberpyme. 
FAO. (2015). Agricultura mundial: Hacia los años 2015-2030.

González, A. E. (2018). Asociatividad y desarrollo económico de los productores de cacao en la provincia de Los Ríos. Killkana Social, 2(4), 49-56. https://doi.org/10.26871/killkana_social.v2i4.369

Grueso, M. P., Gómez, J. H., \& Garay, L. (2012). Procesos de asociatividad empresarial: Aproximaciones conceptuales e impacto económico, social y organizacional. En Borradores de Investigación: Serie documentos Administración, ISSN 0124-8219, No. 44 (Noviembre de 2009) (Número 44).

Gutiérrez, L. M., Rodríguez, L. F., \& Bermúdez, L. T. (2013). Factibilidad de una comercializadora hortícola de economía solidaria en el Distrito de Riego del Alto Chicamocha. Revista Colombiana de Ciencias Hortícolas, 7(1), 62-74. https://doi.org/10.17584/rcch.2013v7i1.2036

IICA. (2017). Institucionalidad de apoyo a la asociatividad en América Latina y el Caribe.

Landini, F. (2016). Problemas de la extensión rural en América Latina. Perfiles Latinoamericanos, 24(47), 47-68. https://doi.org/10.18504/pl2447-005-2016

Liendo, M. G., \& Martínez, A. M. (2013). Asociatividad. Una alternativa para el desarrollo y crecimiento de las Pymes. Encyclopedia of Earth Sciences Series, 1096. https://doi.org/10.1007/978-1-4020-4399-4_33

Maldovan, J., \& Dzembrowski, N. (2009). Asociatividad para el trabajo: Una conceptualización de sus dimensiones. Revista Margen, 55, 1-9.

Mamani, I. (2017). El caso de la Red Andina de Productores de Quinua (FAO).

Marin, Y. F., Mazo, N., \& Olivo, V. C. (2015). Diseño e implementación de un siistema de información geográfico orientado a la web para la gestión agrícola municipal. Universidad de Manizales.

Ministerio de agricultura y desarrollo Rural. (2017). Resolución No 464 de 2017 (p. 179).

Montaña, Z. E. (2016). Estudio de mercado para los productos Hortícolas del programa de agricultura familiar en el municipio de Duitama (Número June). UNIVERSIDAD PEDAGÓGICA Y TECNOLÓGICA DE COLOMBIA.

Montoya, L. A. (2010). Gestión de sistemas de integración empresarial desde una perspectiva biológica. Universidad Nacional de Colombia.

Moreno, D., Uribe, M. C., \& Santiago, L. F. (2011). Comunicación y manejo social para la asociatividad: Mecanismo para la sostenibilidad rural. En Convenio SENA - SAC (Número 00086, p. 27). SENA- SAC.

Narváez, M., Fernandez, G., Gutiérrez, C., Revilla, J., \& Pérez, C. (2009). Asociatividad empresarial: Un modelo para el fortalecimiento de la Pyme en Paraguaná. Multiciencias, 9(2), 157-166.

Ochoa, E. (2016). DISEÑO DE UN SOFTWARE PARA ASOCIACIONES DE PRODUCTORES FRUTÍCOLAS EN LA PROVINCIA DEL TUNDAMA (Número June). UNIVERSIDAD PEDAGÓGICA Y TECNOLÓGICA DE COLOMBIA.

Organización de las Naciones Unidas para el Desarrollo Industrial, \& ONUDI. (2004). Manual de minicadenas productivas. Onudi, January 2004, 150.

Perfetti, J. J., Balcazar, Á., Hernández, A., \& Leibovich, J. (2013). Políticas para el desarrollo de la agricultura en Colombia. En L. I. E. S.A. (Ed.), Políticas para el desarrollo de la agricultura en Colombia.

Rodriguez, D. (2001). Tecnología apropiada para la producción de pequeña escala en el sur: Nuevos Desafíos. Ponencia ante la I Conferencia sobre tecnología. 
Rodriguez, Delia, Parada, M., \& Castillo de Matheus, M. E. (2016). Cadenas productivas para el desarrollo de los municipios Sucre y Francisco de Miranda del estado Táchira, en el marco de la gestión de los consejos comunales. Provincia, 35, 47-70.

Rojas, F. (2013). Formas de asociatividad que prevalecen en la dinamización de las cadenas productivvas agrícolas en Colombia (Vol. 2, Número SGEM2016 Conference Proceedings, ISBN 978-619-7105-16-2 / ISSN 1314-2704). Universidad de la Salle.

Rosales, R. (1997). La asociatividad como estrategia de fortalecimiento de las Pymes. Sela.

Steiner, R., \& Ramírez, T. (2019). Análisis de experiencias de modelos asociativos como mecanismo para el desarrollo empresarial en la ruralidad.

Villanueva, D. F. (2018). Análisis sector agricola y pecuario. En Estudios sobre la Bioeconomía como fuente de nuevas industrias basadas en el capital natural de Colombia (pp. 1-49).

Esta obra está bajo una Licencia Creative Commons Attribución-NoCommercial 4.0 International

(cc) EY-NC 